\title{
CircRNAs: biogenesis, functions, and role in drug-resistant Tumours
}

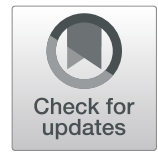

Shuo $\mathrm{Ma}^{1,2,3+}$, Shan Kong ${ }^{1,2,3^{\dagger}}$, Feng Wang ${ }^{1 *}$ and Shaoqing Ju $\mathrm{J}^{1,3^{*}}$

\begin{abstract}
Targeted treatment, which can specifically kill tumour cells without affecting normal cells, is a new approach for tumour therapy. However, tumour cells tend to acquire resistance to targeted drugs during treatment. Circular RNAs (circRNAs) are single-stranded RNA molecules with unique structures and important functions. With the development of RNA sequencing technology, circRNAs have been found to be widespread in tumour-resistant cells and to play important regulatory roles. In this review, we present the latest advances in circRNA research and summarize the various mechanisms underlying their regulation. Moreover, we review the role of circRNAs in the chemotherapeutic resistance of tumours and explore the clinical value of circRNA regulation in treating tumour resistance.
\end{abstract}

Keywords: Circular RNAs (CircRNAs), Tumor resistance, Targeted treatment, Self-circularize, Functions

\section{Background}

Circular RNAs (circRNAs) are newly recognized noncoding RNAs that are considered small endogenous RNAs with a wide distribution, considerable variety, and multiple regulatory functions [1]. In 1976, Sanger et al. discovered the first circRNA in viroids [2]. Since then, tens of thousands of circRNAs have been identified in multiple cell lines and species [3-5], including fungi, protozoa, plants, worms, fish, insects, mice and humans [6-8]. CircRNAs are abundant-approximately oneeighth of the genes in the human transcriptome can produce detectable circRNAs, and the expression levels of these circRNAs are more than ten times those of the corresponding linear mRNAs $[9,10]$. Additionally, circRNAs are more stable than linear RNAs because of their covalent closed-loop structure and lack of free terminal ends, which confers resistance to degradation by ribonuclease R (RNase R) [11]. Moreover, circRNAs are evolutionarily conserved. Approximately 15,000 human circRNA sequences can be detected in mouse or

\footnotetext{
*Correspondence: richardwangf@163.com; jsq814@hotmail.com

'Shuo Ma and Shan Kong contributed equally to this work.

'Department of Laboratory Medicine, Affiliated Hospital of Nantong

University, NO.20, Xisi Road, Nantong 226001, Jiangsu, China

Full list of author information is available at the end of the article
}

rat genomes $[5,12]$. CircRNAs can also be used to classify and identify different tumour types due to their advantage of cell type-, tissue-, and developmental stagespecific expression and because different subtypes of circRNAs can be produced [13-16]. Considering the above observations, we believe that circRNAs have great research potential. As research has progressed, various biological functions of circRNAs have been revealed. CircRNAs can act as "sponges" for microRNAs (miRNAs) and affect the function of miRNA target genes [17]. In addition, circRNAs can bind to specific RNA binding proteins (RBPs), thereby affecting the function of the parental genes [18-20]. Intriguingly, accumulating evidence shows that circRNAs can encode proteins/peptides that are involved in tumour pathogenesis and progression [21-23]. The unique properties and biological functions of circRNAs demonstrate the importance of circRNAs in tumorigenesis, proliferation, metastasis, invasion, and drug resistance, which also suggests the possibility that circRNAs can be used as biomarkers and tumour therapeutic targets [24-26].

Tumour treatment remains a serious medical problem worldwide. Despite clinical advances, chemotherapy and radiotherapy are still the preferred methods for tumour 
treatment. The development of drug resistance means that tumour cells can evade the effects of antitumour drugs with different structures and functions, and drug resistance has proven an important obstacle to tumour treatment $[27,28]$. Due to the evolution of drug resistance, a considerable number of cancer patients experience local recurrence and distant metastasis, which may lead to poor prognosis and higher tumour mortality. Although extensive studies have been conducted, the mechanisms of and responses to drug resistance in tumours remain unclear. Several studies have shown that miRNAs and long non-coding RNAs (lncRNAs) are associated with chemotherapeutic resistance $[29,30]$. However, information on the involvement of circRNAs in drug resistance and the underlying regulatory mechanisms is scarce.

In this review, we provide an overview of the biosynthesis and clinically significant of circRNAs and describe the differential expression of circRNAs in drug-resistant tumours. We emphasize potential regulatory mechanisms of circRNAs to provide a basis for clinical treatment.

\section{Biogenesis and characteristics of circRNAs Biological origin of circRNAs}

CircRNAs are divided into three categories according to their source: exonic circRNAs (EciRNAs), exon-intron circRNAs (EIciRNAs), and intronic circRNAs (CiRNAs) $[1,31,32]$. Most circRNAs are formed by exon skipping during pre-messenger RNA (pre-mRNA) transcription to produce a lariat structure containing exons, which is then spliced internally to release introns and form EciRNAs composed of exons [33-35]. Alternatively, the tail end of the downstream 3' splicing donor site in the exon binds to the upstream $5^{\prime}$ splicing receptor site, resulting in base pairing of the donor and receptor sites, which mediates exon circularization to form circRNAs. Generally, circRNAs are produced from a single exon, but circRNAs containing several exons can also be formed [3]. The exons that form circRNAs are mainly contained in the same gene. Further study indicated the generation of circRNAs produced by exons from different genes due to chromosomal translocations and other reasons in vivo; these circRNAs are called fusion circRNAs (fcircRNAs), and most are oncogenes [36]. In addition, read-through circRNAs (rt-circRNAs) composed of two adjacent gene exons on the same DNA strand, were found by exon sequencing [37]. Rt-circRNAs accounted for only a small fraction ( $2.5 \%$ on average) of all circRNAs in each sample. The expression of rt-circRNAs is lower than that of total circRNAs, and the formation of rt-circRNAs is related to read-through of RNA polymerase II (RNA Pol II) at the gene locus [37]. During the formation of circRNAs, if introns between exons are retained, circular transcripts form EIciRNAs composed of both exons and introns $[9,38]$. The interconnections of introns cause the formation of CiRNAs after the lariat structure undergoes internal reverse splicing [32]. The mechanisms of circRNA biogenesis are depicted in Fig. 1.

CircRNA biogenesis is regulated by many factors. Rei et al. found that mammalian-wide interspersed repeats (MIRs) mediate the biogenesis of circRNAs. Knockout of upstream or downstream MIRs in human and mouse genomes significantly inhibited the production of CDR1as [39]. $\mathrm{N}^{6}$-methyladenosine $\left(\mathrm{m}^{6} \mathrm{~A}\right)$ has been demonstrated to affect the production of circRNAs [40]. From the pachytene stage to the round cell stage of spermatogenesis after meiosis, a large number of circRNAs with an extended $\mathrm{m}^{6} \mathrm{~A}$-modified open reading frame (ORF) are produced. Anti- $\mathrm{m}^{6} \mathrm{~A}$ RNA binding protein immunoprecipitation (RIP)-seq data showed that as spermatogenesis progresses, the number of $\mathrm{m}^{6} \mathrm{~A}$-carrying circRNAs increases, proving that $\mathrm{m}^{6} \mathrm{~A}$ can mediate the biogenesis of circRNAs. Di et al. confirmed that some circRNAspecific $\mathrm{m}^{6} \mathrm{~A}$ loci may be related to the production of circRNAs. The authors found that circZNF609 contains a circRNA-specific $\mathrm{m}^{6} \mathrm{~A}$ locus and that when the specific site is mutated, the production of circZNF609 is significantly inhibited [41]. In addition, base pairing between Alu elements and dimerization of RBPs in introns play essential regulatory roles in the formation of circRNAs alternative splicing [33, 42]. For example, the protein HQK is encoded by quaking (QKI) [43], fused in sarcoma (FUS) [44], and serine/arginine-rich splicing factor 3 (SRSF3) [45]. Via the Mini gene reporting system constructed in Drosophila cells, Liang et al. found that the trans splicing factor SR protein and heterogeneous nuclear ribonucleoproteins (hnRNPs) could interact with intron repeat sequences. In addition to the genes related to transcription termination, SR and hnRNPs can significantly increase the abundance of circRNAs [46]. A study showed that ATP-dependent RNA helicase A (DHX9) can promote the unwinding of double-stranded RNA structures and that its knockout can significantly increase the number and types of circRNAs [47]. The protein product of the interleukin enhancer-binding factor 3 (ILF3) gene, NF90/NF110, promotes the formation of circRNAs and participates in host antiviral mechanisms by stabilizing CiRNA pairs [48]. Studies have also shown that the parental genes of circRNAs with high abundance and constitutive detection have longer and larger introns on both sides of the circRNA [16] and contain greater numbers of repeating elements [37] than parental genes of circRNAs with low abundance and limited expression. However, compared with the parental genes of circRNAs, parental genes of rt-circRNAs have longer introns and more repeating elements in their flanking sequences [37]. These elements draw the two splice sites 


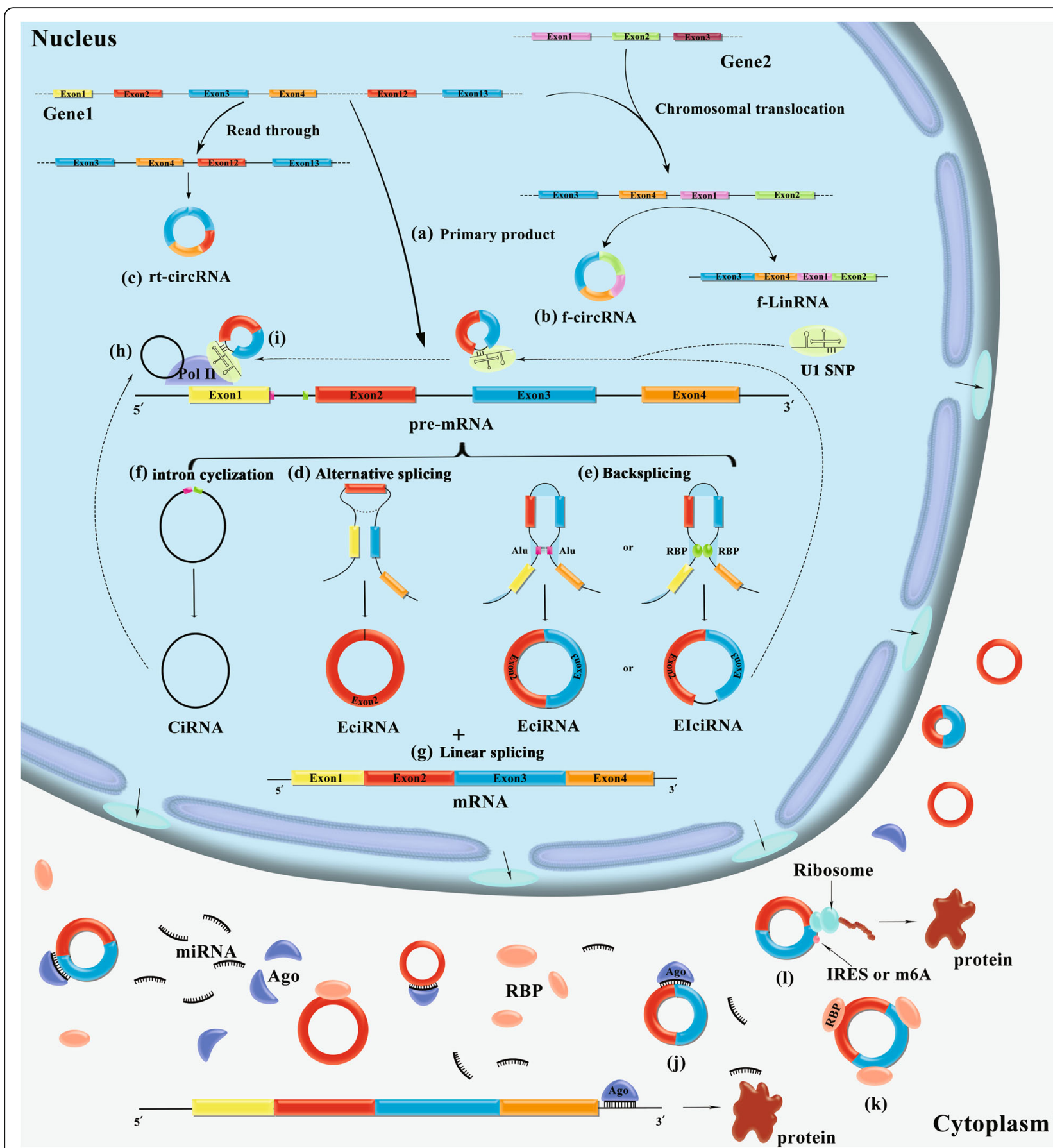

Fig. 1 Biogenesis and function of circRNAs. a. The main product of gene transcription, pre-mRNA. b. In vivo, chromosomal translocations and other reasons may cause CircRNAs to be produced by exons of different genes, which are called fusion CircRNAs(f-circRNAs). c. Two adjacent gene exons on the same DNA chain can form circRNAs, read through circRNA (rt-circRNAs). $\mathbf{d}$. During pre-mRNA transcription to produce a lariat structure containing exons, which is then spliced internally to release introns and form EciRNAs composed of exons. e. the tail end of the downstream 3' splicing donor site in the exon binds to the upstream 5' splicing receptor site, resulting in base pairing of the donor and receptor sites, which mediates exon circularization to form circRNAs or EciRNA. It is regulated by Alu, RBPs, and parental gene exons. f. The interconnections of introns cause the formation of CiRNAs after the lariat structure undergoes internal reverse splicing. g. Liner mRNA: singlestranded ribonucleic acids are carrying genetic information. $\mathbf{h}$. Interaction between CiRNA and Pol II promotes parental gene transcription. i. ElciRNAs interact with U1-SNP and Pol II to enhance gene expression. $\mathbf{j}$. CircRNAs can affect the occurrence and development of diseases as competitive binding miRNA of ceRNA. $\mathbf{k}$. CircRNAs act as RBPs scaffold sponge to regulate variable splicing of transcripts, transcription of parent genes, and post-transcriptional translation. I. CircRNAs can be modified with IRES sequence and $\mathrm{m}^{6} \mathrm{~A}$ to facilitate the translation of circRNAs 
closer together and facilitate reverse splicing [7]. Josh et al. found that parental genes of circRNAs tended to form multiple circular isomers and that the number of isomers formed was proportional to the number of exons in the parental gene [37]. However, the expression levels of circRNAs and the abundance of mRNA produced by the parental gene were not significantly related $[4,49]$. In addition, circRNAs are downregulated in most tumours and are negatively correlated with cell proliferation [37]. The substantial accumulation of circRNAs in ageing neural tissue can also be explained by this observation [50].

\section{Characteristics of circRNAs}

Unlike linear RNAs, circRNAs are single-stranded, covalently closed circular transcripts without 5 'caps and 3' tails [9]. Thus, circRNAs are considered to be more stable than linear RNAs. In 2006, Hitoshi et al. demonstrated that circRNAs are not easily degraded by RNA exonucleases [51]. In 2015, Yehoshua et al. found that most circRNAs have longer half-life than their linear counterparts [52], especially in non-dividing cells [53]. However, because circRNAs are relatively stable, they can accumulate in cells with slower rates of division and thus affect cell functions. To date, five pathways of circRNA self- circularization that manage this limitation have been found (Fig. 2).

(1) MiR-671 binds to a highly complementary miRNA binding site in ciRS-7 (also called CDR1as), thereby triggering the cleavage of Argonaute 2 (Ago2) [54, 55]. Argonaute proteins play a role in RNA interference (RNAi) [56]. This cleavage can be enhanced by miR-7, which recruits the miR-671 silencing complex to ciRS-7 or retains it there through an undefined mechanism [55].

(2) CircRNAs containing $\mathrm{m}^{6} \mathrm{~A}$ sequences can interact with YTH domain-containing family protein 2 (YTHD F2) (an $m^{6} A$ reader) [57] and possibly self-circularize via two mechanisms. CircRNAs that contain binding sites for heat-responsive protein 12 (HRSP12) (an adaptor protein) are preferentially degraded via ribonuclease $\mathrm{P}$ (Rnase P)/MRP-mediated endoribonucleolytic pathways [58], which are coupled to the CCR4-NOT complexmediated deadenylation pathway via cooperative binding of HRSP12 and YTHDF2 to circRNAs containing $\mathrm{m}^{6} \mathrm{~A}$ [59]. CircRNAs containing $\mathrm{m}^{6} \mathrm{~A}$ lack HRSP12 binding sites, and YTHDF2 may still interact with HRSP12 and induce decay, albeit with low efficiency [59]. The HRSP12 binding site and the Rnase P/MRP cleavage site are located upstream and downstream of the YTHDF2 recognition site, respectively [59].

(3) CircRNAs tend to form a 16-26 bp small ring structure, which can bind and inhibit double-stranded DNA in the RNA-activated protein kinase (PKR) gene [60]. When cells are stimulated or infected with viruses, ribonuclease L (Rnase L) is activated and degrades circRNA molecules; subsequently, PKR is released and activates the downstream antiviral mechanism [60].

(4) GW182 mediates the degradation of circRNAs in Drosophila cells, as determined in studies based on RNAi library screening. Interference with GW182 minimally affects the abundance of nuclear circRNAs but, conversely, significantly decreases the abundance of cytoplasmic circRNAs. Overexpression of GW182 can lead to a decrease in the abundance of related circRNAs [61]. Moreover, circRNAs can be enriched significantly after interference with the three human homologues of the GW182 gene (TNRC6A, TNRC6B, and TNRC6C), indicating that TNRC6A/B/C are involved in the degradation of circRNAs [61].

(5) UPF1 and G3BP1 mediate the structure-mediated RNA decay (SRD) of mRNA. The abundances of mRNAs with a complex 3' untranslated region (3'UTR) structure is less altered after UPF1 knockdown than those of mRNAs with less complex 3'UTR structures. Subsequently, this mechanism was confirmed to apply to circRNAs. The authors knocked down UPF1 and G3BP1 in DLD cells containing circRNAs with complex structures and analysed the abundance trends. The abundances of circRNA molecules with more complex structures changed less than those of circRNA molecules with less complex structures after knocking down UPF1 and G3BP1. Thus, circRNA molecules with complex structures may be regulated by the SRD mechanism [62].

In addition, studies have shown that circRNAs may be secreted from cells via exosomes [63, 64]; most of these circRNAs mediate inter-cellular communication through exosomes $[65,66]$. However, whether this event is related to the self-regulation of circRNAs and whether the degradation of these circRNAs affects their cellular function are unclear.

\section{Nuclear and cytoplasmic transport of circRNAs}

Most circRNAs are exported to the cytoplasm after formation, acting as miRNA sponges, binding with RBPs, or encoding proteins [67-69]. Huang et al. found that Hel25E is a vital regulator of post-transcriptional nucleation of circRNAs in Drosophila. Both of the Hel25E homologues, URH49 (DDX39A) and UAP56 (DDX39B), can mediate the nuclear export of circRNAs [70]. Interestingly, UAP56 and Hel25E are responsible mainly for the nuclear export of long circRNAs, whereas URH49 is responsible mainly for the nuclear export of short circRNAs [70]. Experimental results showed that circRNAs of different lengths exhibit different protein recognition characteristics due to point mutations in four amino acids located in the middle of the protein sequence [70]. In addition, circRNAs can rely on $\mathrm{m}^{6} \mathrm{~A}$ for nuclear export [71]. $\mathrm{m}^{6} \mathrm{~A}$-modified circNSUN2 can bind $\mathrm{YTH}$ 


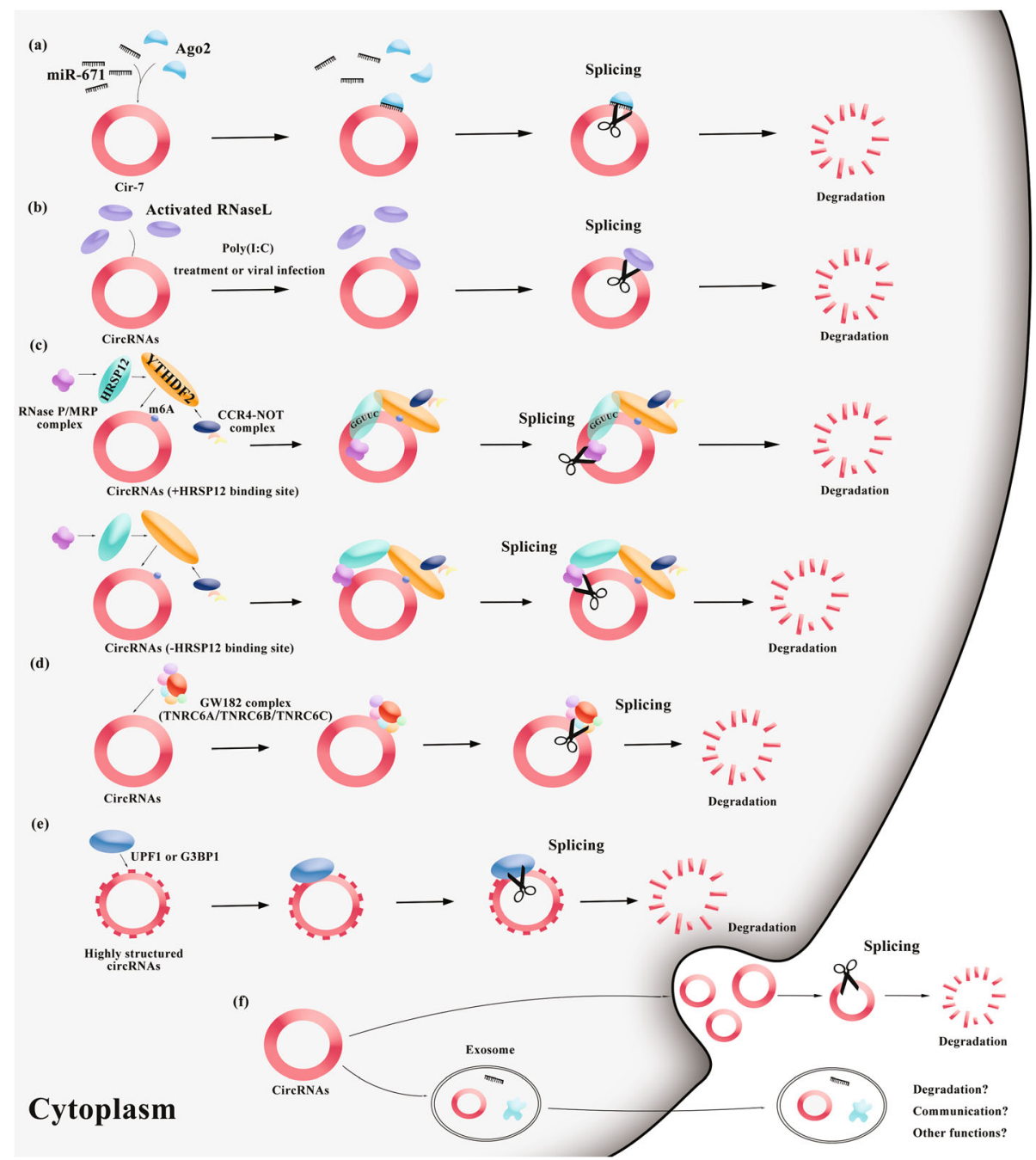

Fig. 2 CircRNAs self-circularize mechanisms. a. MiR-671 binds to a highly complementary miRNA binding site in ciRS-7, thereby triggering the cleavage of $A G O 2$. b. When cells are stimulated or infected by viruses, RNase $L$ activates and degrades circRNAs molecules. c. CircRNAs with $m^{6} A$ sequences have two ways of self-renewing. $\mathbf{d}$. The GW182 gene in drosophila cells and the human homologous genes TNRC6A, TNRC6B, and TNRC6C mediate the apoptosis of circRNAs. e. The regulation of UPF1 or G3BP1 can degrade CircRNAs with complex structures. f. CircRNAs are removed from the cytoplasm by exosomes or direct release into the extracellular space

domain-containing family protein 1 (YTHDC1) and promote its nuclear export. YTHDC1 is a reader of RNA $\mathrm{m}^{6} \mathrm{~A}$ [72]. CircNSUN2 interacts with YTHDC1 and can be enriched by antibodies against $\mathrm{m}^{6} \mathrm{~A}$. This modification mediates its interaction with YTHDC1. After interference with YTHDC1, the subcellular distribution of circNSUN2 changed, and the abundance of nuclear circNSUN2 increased [72]. This phenomenon was confirmed with fluorescence in situ hybridization (FISH) positioning analysis [71].

\section{CircRNA functions}

With the development of research, the biological functions of circRNAs have been widely revealed [32, 73] (Fig. 1 and Table 1).

\section{MiRNA sponges}

Numerous studies have demonstrated that circRNAs can play a vital regulatory role as miRNA sponges in tumours. The most representative example is ciRS-7, which has more than 70 selectively conserved miRNA targets [17]. CiRS-7 can inhibit the activity of miR-7 and lead to an increased level of the target of miR-7. In addition, the testicular-specific sex-determining region $\mathrm{Y}$ circRNA (circ-Sry), can act as a miR-138 sponge. Gao and Ye et al. used microarray analysis to select the most significantly upregulated carcinogenic factor (circ-sox4) in lung adenocarcinoma (LUAD) tissues and found that circ-sox 4 promoted the proliferation, invasion, and migration of LUAD cells by sponging miR-1270 and upregulating PLAGL2 [74]. In bladder cancer, circTCF25 acts 
Table 1 The mechanisms and biological functions of main circRNAs

\begin{tabular}{|c|c|c|c|c|}
\hline circRNA & Mechanisms & Location & Functions & Refs \\
\hline $\begin{array}{l}\text { CIRS- } \\
7(\text { CDR1as) }\end{array}$ & Sponges miR-7 & cytoplasm & Regulates the nervous system and promotes drug resistance & $\begin{array}{l}{[17,105} \\
157,158]\end{array}$ \\
\hline circ-Sry & Sponges miR-138 & cytoplasm & Relates to gender determination & [17] \\
\hline circ-SOX4 & $\begin{array}{l}\text { Sponges miR-1270 and up-regulated } \\
\text { PLAGL2 }\end{array}$ & cytoplasm & $\begin{array}{l}\text { Promotes the proliferation, invasion and migration of LUAD } \\
\text { cells }\end{array}$ & [74] \\
\hline circTCF25 & $\begin{array}{l}\text { Sponges miR-103a-3p and miR-107 } \\
\text { increased the expression of CDK6 }\end{array}$ & cytoplasm & Promotes the proliferation of bladder cancer cells & [75] \\
\hline circ-TFF1 & miR-326/TFF1 axis & cytoplasm & Carcinogenesis in breast cancer & [76] \\
\hline circPTPRA & Sponges miR-96-5p & cytoplasm & Inhibition of EMT in NSCLC cells & [78] \\
\hline circRIP2 & $\begin{array}{l}\text { Sponges miR-1305, activated Tgf 2/ Smad3 } \\
\text { pathway }\end{array}$ & cytoplasm & $\begin{array}{l}\text { EMT is induced to promote the proliferation, invasion and } \\
\text { migration of bladder cancer }\end{array}$ & [79] \\
\hline circAMOTL1L & Sponges miR-193a-5p & cytoplasm & Promotes EMT in prostate cancer cells & [80] \\
\hline CircCSNK1G3 & Sponges miR-181b/d & cytoplasm & Stabilize miRNAs and promote cell proliferation & [49] \\
\hline CircMb1 & Combines with the MBL & cytoplasm & Relates to neuromodulation & [1] \\
\hline Ci-ankrd52 & Binds to RNA Pol ॥ & nucleus & Cis-regulation promotes transcription of ANKRD52 & [32] \\
\hline CircllF3」 & Interacts with U1 snRNP and RNA Pol II & nucleus & Enhances the transcription of parental genes & [81] \\
\hline circPAIP2 & Interacts with U1 snRNP and RNA Pol II & nucleus & Enhances the transcription of parental genes & [81] \\
\hline circMYBL2 & Binds to the protein PTBP1 & cytoplasm & Promotes the development of flt3-itd mutant white blood & [82] \\
\hline circAmotl1 & Binds PDK1 and AKT1 & cytoplasm & $\begin{array}{l}\text { Protein scaffolds promote phosphorylation and promote } \\
\text { cardiac protective nuclear translocation }\end{array}$ & [20] \\
\hline circFOXO3 & $\begin{array}{l}\text { Binds to the complex of ID-1, CDK2-p21 and } \\
\text { p53-MDM2 }\end{array}$ & cytoplasm & Affects cell senescence, cell cycle and apoptosis & {$[83,84]$} \\
\hline circZNF609 & Translation template & cytoplasm & Specifically controls the proliferation of myoblasts & {$[23]$} \\
\hline circSHPRH & Translation template & cytoplasm & Inhibits cell proliferation and tumor suppressors & [96] \\
\hline circ-LINCPINT & Translation template & cytoplasm & Inhibits cell proliferation and tumor suppressors & [97] \\
\hline circFBXW7 & Translation template & cytoplasm & $\begin{array}{l}\text { Inhibits the proliferation of cancer cells and the acceleration } \\
\text { of the cell cycle }\end{array}$ & [98] \\
\hline circPPP1R12A & Translation template & cytoplasm & Inhibits cell proliferation and tumor suppressors & [21] \\
\hline
\end{tabular}

as a miRNA sponge, suppressing the functions of miR103a-3p and miR-107 in tumour tissues and increasing the expression of cyclin-dependent kinase 6 (CDK6), leading to tumour cell proliferation [75]. Pan et al. found a carcinogenic circRNA, circ-TFF1, which is produced from the host gene trefoil factor 1 (TFF1) located on chromosome 21q22.3, and found that circ-TFF1 plays a carcinogenic role in breast cancer by regulating the miR-326/TFF1 axis [76]. All of the above results suggest that miRNA sponging by circRNAs is a common phenomenon [17].

Intriguingly, studies have also shown that circRNAs can act as competing endogenous RNAs (ceRNAs) to influence epithelial-mesenchymal transition (EMT) in tumours. EMT can affect the expression patterns of cell adhesion, migration, proliferation, apoptosis, and other genes and can modify cell behaviour to induce drastic changes [77]. First, a study showed that the expression of hundreds of circRNAs is induced during EMT in humans [43]. Then, Wei et al. identified the tumour suppressor circPTPRA through an initial microarray analysis of non-small cell lung cancer (NSCLC) samples and found that circPTPRA inhibited EMT in NSCLC cells by binding to miR-96-5p [78]. The tumour suppressor circRIP2 induces EMT in bladder cancer through competitive binding to miR-1305 and activation of the transforming growth factor- $\beta 2$ (Tgf- $\beta 2$ )/Smad3 pathway to promote the proliferation, invasion, and migration of bladder tumour cells [79]. However, circAMOTL1L acts as a sponge by binding to miR-193a-5p in prostate cancer (Pca) cells, which alleviates the inhibitory effects of miR-193a-5p on the protocadherin (PCDHA) gene cluster, promotes prostate cancer cell EMT in vivo, and leads to the growth of prostate cancer in vivo [80]. To date, circRNAs have been found to stabilize miRNAs in addition to acting as molecular sponges for miRNAs. Through miRNA expression profiling and analysis of AGO2-CLIP seq data, researchers showed that circCSNK1G3 may function by binding to miR-181b/ d. Interestingly, the interaction of circCSNK1G3 with $\mathrm{miR}-181 \mathrm{~b} / \mathrm{d}$ does not inhibit the activity of miR-181b/ $\mathrm{d}$, but the reduction in circCSNK1G3 expression abolishes the ability of $\mathrm{miR}-181 \mathrm{~b} / \mathrm{d}$ to inhibit the 
expression of its target genes (CBX7, CDK1, and CDC25A) [49]. This pattern is inconsistent with the usual pattern of circRNA action. However, competitive binding of circRNAs to miRNAs remains the primary mechanism underlying their regulatory functions in tumours. Research on circRNAs can provide potential targets for cancer treatment.

\section{RBPs}

RBPs are a broad class of proteins that interact with RNA molecules and can play key roles in RNA posttranscriptional regulation, tissue development, and diseases [68].

\section{CircRNAs bind to RBPs to regulate transcript splicing and parental gene transcription}

As a regulatory protein of circRNAs, muscleblind (MBL) in Drosophila can promote the circularization of mRNA precursors. The MBL circRNA (circMb1) and its flanking introns contain conserved sites that bind specifically to MBL. At low concentrations of MBL, the MBL gene produces a linear mRNA transcript, which is translated into the MBL protein. In contrast, at high concentrations of MBL, the MBL protein binds to its precursor RNA, prompting the formation of circMbl from exon 2, preventing the production of additional MBL protein and exerting negative feedback regulation [1]. An enriched CiRNA, ci-ankrd52, accumulates mainly in the nucleus and promotes the transcription of ANKRD52 through cis regulation of RNA Pol II. Knockout of ciankrd52 can reduce the expression of its parental gene [32]. Additionally, EIciRNAs, which are composed of exons and introns, promotes transcription. A study showed that EIciRNAs such as circIIF3J and circPAIP2, which are localized mainly in the nucleus, interact with the U1 small nuclear ribonucleoprotein (U1 snRNP) and RNA Pol II to enhance the transcription of their parental genes. Knockout of circEIF3J and circPAIP2 reduced the transcript levels of EIF3J and PAIP2, respectively [81]. Interestingly, both of these EIciRNAs are present in the nucleus and act as cis-regulatory elements to promote the expression of their parental genes, but the other potential functions of these EIciRNAs, such as trans regulation, are unknown.

\section{CircRNAs bind to RBPs to regulate translation and act as protein scaffolds}

CircRNAs can bind to specific RBPs and regulate the interaction between RBPs and their target RNAs. Sun et al. found that circMYBL2 regulates the mRNA translation efficiency of the oncogene FMS-like tyrosine kinase-3 (FLT3) by recruiting the RBP PTBP1, thus promoting the occurrence and development of white blood cells harbouring FLT3-internal tandem duplication
(ITD) mutations [82]. That study was the first to report that circRNAs play a decisive regulatory role in the translation process as RNA-protein complexes [82]. In addition, circRNAs may act as a "scaffold" for RBPs, binding to multiple RBPs and promoting stable interactions through the potentially increased stability of circRNA transcripts. For example, circAmotl1 physically binds to 3-phosphoinositide-dependent protein kinase 1 (PDK1) and protein kinase B (AKT1) to promote PDK1dependent AKT1 phosphorylation. In addition, circAmotl1 promotes the cardioprotective nuclear translocation of PAKT [20]. CircFOXO3 can affect cell senescence, the cell cycle, and apoptosis by interacting with the antiageing 132 protein ID-1, the CDK2-p21 complex, and the p53-MDM2 complex [83, 84]. In summary, we speculate that circRNAs may also function as sequence-targeting elements. Interactions between circRNAs and RBPs can also mediate various biological activities, such as cell proliferation, differentiation, motility, apoptosis, senescence, and the cellular response to oxidative stress, through posttranscriptional regulation [83, 85]. Some studies have shown that specific proteins can synergistically bind to multiple circRNAs in the cytoplasm to produce a molecular repository of proteins that respond rapidly to extracellular stimuli. This process can achieve a rapid immune response after viral infection [18].

\section{Protein translation}

CircRNAs are considered non-coding RNAs because they lack 3' and 5' ends [86]. However, in 2015, Abe et al. provided strong evidence that endogenous circRNAs can act as translation templates [87]. In the acellular Escherichia coli translation system, circRNAs with an infinite ORF were effectively translated through the roll-ring amplification technique (RCA). These results suggest that circRNAs without poly (A) tail or cap structures can be translated into proteins [87]. Since that discovery, accumulating evidence has shown that circRNAs can encode regulatory proteins/peptides [88] and that these functional proteins/peptides can regulate biological processes and affect tumour occurrence, invasion, and metastasis [89].

\section{Translation patterns based on the IRES}

Eukaryotic mRNAs are translated through a typical capdependent translation mechanism [90]. However, under conditions such as cellular stress exposure or viral infection, mRNA translation can be initiated through a capindependent alternative translation mechanism via the internal ribosome entry site (IRES) [91]. The IRES can directly recruit ribosomes, perform ribosomal assembly and in-frame protein translation, and initiate protein translation independent of the $5^{\prime}$ cap structure and direct translation [92]. In 2017, Legnini et al. found that circZNF609 in mouse and human muscle cells explicitly 
controls the proliferation of muscle cells. During myogenesis, heat shock activates circZNF609 translation, and the UTR of circZNF609 can act as an IRES to support protein translation in a splice-dependent and capindependent manner [23]. Surprisingly, additional studies have demonstrated that through IRES-mediated translation, circRNAs produce peptides that regulate tumour biological functions [93-95]. CircSHPRH [96], circLINCPINT [97], circFBXW7 [98], and circPPP1R12A [21] can translate proteins or short peptide chains in glioma by relying on the IRES-mediated translation mechanism. CircRNAs with more than 50 nucleotides (nt) may contain a hexamer similar to an IRES [88], a feature that indicates the universality of the IRES-mediated circRNA translation mechanism.

\section{Translation modes based on $m^{6} A$}

In addition to the IRES-mediated circRNA translation mechanism, another important cap-independent translation mechanism is mediated by the presence of methylated adenosine residues in the form of $\mathrm{m}^{6} \mathrm{~A}$ in the 5'UTR [99]. $\mathrm{m}^{6} \mathrm{~A}$ modification is quite common in mRNAs and ncRNAs [100, 101]. Recently, circRNAs were found to contain numerous short sequences with $\mathrm{m}^{6} \mathrm{~A}$ sites [102]. Yun et al. found that $\mathrm{m}^{6} \mathrm{~A}$ in the $5^{\prime} \mathrm{UTR}$ promoted cap-independent translation during heat stress through the protective mechanism of YTHDF2 [102]. In addition, this group found that numerous circRNAs are methylated, and hundreds of endogenous translatable circRNAs containing $\mathrm{m}^{6} \mathrm{~A}$ sites were identified by sequencing [102]. Collectively, the above findings demonstrate that the $\mathrm{m}^{6} \mathrm{~A}$-mediated translation is typical for circRNAs $[103,104]$. The IRES-mediated and $\mathrm{m}^{6} \mathrm{~A}-\mathrm{me}-$ diated translation mechanisms are two primary capindependent circRNA translation mechanisms. More mechanisms by which circRNAs are translated into proteins remain to be discovered.

\section{Potential of circRNAs as biomarkers}

The early symptoms of most tumours are not obvious, and patients often miss the best opportunity for treatment due to the lack of specific early diagnostic markers. Therefore, identification of accurate biomarkers and therapeutic targets is urgently needed. CircRNAs are potential biomarkers for the early diagnosis, metastasis, prognosis, and drug resistance of tumours due to their stable structure [11], long half-life [52], tumour specificity [16], and ability to be detected in various body fluids [105-107]. Regarding the early diagnosis of tumours, Ren et al. found that hsa_circ_0043265 exhibited low expression in NSCLC tissues and cells and that it could increase the expression of FOXP2 through sponging miR25-3p, thus inhibiting NSCLC progression. Thus, hsa circ_0043265 could be used as a biomarker for the early diagnosis of NSCLC [108]. Li et al. found that circMYLK was highly expressed in liver cancer tissues and cell lines and promoted the occurrence and development of liver cancer by regulating the miR-362-3p/Rab23 axis, thus providing a basis for the early diagnosis and treatment of liver cancer [109]. Regarding tumour metastasis, Yang et al. found that the expression of circPTK2 was upregulated in colorectal cancer (CRC) tissues and that the survival rate of colorectal cancer patients with high circPTK2 expression was lower than that of colorectal cancer patients with low circPTK2 expression. CircPTK2 promotes EMT in colorectal cancer cells both in vivo and in vitro by binding to vimentin at Ser38, Ser55, and Ser82. These results suggest that circPTK2 may be a therapeutic target for metastatic colorectal cancer and a promising biomarker for the early diagnosis of metastasis [110]. Regarding tumour prognosis, Guo et al. found that circBFAR expression was upregulated in pancreatic ductal adenocarcinoma (PDAC). CircBFAR expression was positively correlated with the tumour-node-metastasis (TNM) stage and was associated with poor prognosis in PDAC patients. This circRNA enhancing EMT by binding miR34b-5p and activating the Met/PI3K/Akt signalling pathway, finally promoting the development of PDAC. CircBFAR could be used as a prognostic indicator and therapeutic target for PDAC [111]. In addition, the expression levels hsa_circ_0124055 and hsa_circ_0101622 in tumour tissues and plasma of patients with thyroid cancer are significantly increased, and the overall survival times of patients with a high expression level of either circRNA were shorter than those of patients with a low expression level of either circRNA. These results suggest that both of these circRNAs are helpful biomarkers for the prognosis and diagnosis of thyroid carcinoma and can be used as clinical therapeutic targets [112]. In addition, regarding drug resistance, hsa_circ_0006528 [113], circMTO1 [114], circ_0001546 [115], and circ-LARP4 [116] exhibit abnormal expression levels in drug-resistant cells, suggesting that they could be used as diagnostic markers for drug resistance in tumours.

CircRNAs have become accepted as biomarkers for multi-stage tumours. If circRNA detection methods can be effectively applied in clinical practice, these methods could be used to diagnose tumours in patients as early as possible and avoid patient distress.

\section{Mechanisms of circRNAs in drug resistance}

The unique properties and biological functions of circRNAs have indicated their importance in tumorigenesis, tumour growth, metastasis, invasion, drug resistance and radioresistance. Further, these results suggest that circRNAs may become new biomarkers or therapeutic targets for tumours [24-26]. As shown in Fig. 3 and Table 2, we summarize the potential mechanisms of 
circRNAs in drug-resistant tumours to provide evidence for clinical treatment strategies.

\section{Lung cancer}

Cisplatin (CDDP), pemetrexed (MTA), paclitaxel (PTX), and gefitinib are effective targeted drugs for lung cancer [117-119]. Numerous experiments have demonstrated that circRNAs play a regulatory role in drug resistance in lung cancers, including LUAD, small cell lung cancer (SCLC), and NSCLC. CircPVT1 is upregulated in LUAD tissues and cell lines with resistance to CDDP and MTA. CircPVT1 was found to mediate CDDP and MTA resistance via the miR-145-5p/ABCC1 axis. CircPVT1 knockout sensitizes tumour cells to CDDP and MTA [120]. Another study showed that upregulation of CDR1-as in LUAD tissues and cell lines is related to PTX and CDDP insensitivity in LUAD patients. CDR1-as promotes chemotherapeutic resistance to PTX and CDDP in LUAD patients through the epidermal growth factor receptor (EGFR)/phosphatidylinositol 3-kinase (PI3K) signalling pathway [105]. In SCLC, circESRP1, which can directly bind to miR-93-5p and upregulate the expression of its downstream target genes Smad7/cyclin-dependent kinase inhibitor 1 (p21), is significantly downregulated in drugresistant cells. Finally, a negative feedback loop is formed. At the same time, TGF- $\beta$-mediated EMT is regulated to enhance the sensitivity to CDDP, adriamycin (ADM), and etoposide (DT-PACE). In addition, both overexpression of circESRP1 and inhibition of the TGF- $\beta$ signalling pathway can change the tumour response to chemotherapy [121]. Circ_0002483 is downregulated in NSCLC cells and can regulate its target genes growth factor receptor-bound protein2 (Grb2), forkhead box protein O1 (Foxo1), and forkhead box protein O3 (Foxo3) by sponging miR-182-5p, thus enhancing the sensitivity of NSCLC cells to PTX [122]. In another study, circ_0076305 and circRNA_103762 were found to be significantly upregulated in CDDPresistant NSCLC tissues and cell lines. Circ_0076305 can regulate CDDP resistance in NSCLC cells by binding to miR-296-5p and acting on the target gene STAT3 [123]. CircRNA_103762 promotes CDDP resistance in NSCLC by targeting DNA damage-inducible transcript 3 (CHOP) [124]. Hsa_circ_0001946 is downregulated in NSCLC cells and has been proven to reduce the sensitivity of NSCLC cells to CDDP by regulating the nucleotide excision repair (NER) signalling pathway; promoting the survival, proliferation, migration, and invasion of NSCLC cells; and inhibiting apoptosis [125]. Finally, upregulation of hsa_circ 0004015 in NSCLC cells can enhance the resistance of lung cancer cells to gefitinib via the circRNA/miR1183PDK1 axis [25].

\section{Breast cancer}

Chemotherapy is an effective method to prevent breast cancer recurrence and metastasis after surgical treatment [126]. However, chemotherapeutic resistance remains a major problem. Hsa_circ_0006528 is upregulated in ADM-resistant breast cancer cells, possibly via the circRNA/miR-7-5p/Raf1 axis [113]. Low expression levels of miR-7 have long been proven to confer resistance to breast cancer chemotherapy [127]. In another study of ADM-resistant breast cancer, circKDM4C downregulation was found to inhibit tumour progression and alleviate $\mathrm{ADM}$ resistance by regulating the miR-548p/PBLD axis [128]. Additionally, the expression level of circMTO1 (hsa_circ_007874) in monastrol-resistant breast cancer cell lines is significantly reduced compared with that in monastrol-sensitive breast cancer cell lines, and overexpression of circMTO1 can reverse monastrol resistance through the circRNA/TNF receptor-associated factor 4 (TRAF4)/Eg5 pathway [129]. In addition, Ma et al. found that circMOTL1, which may play an essential role in the PTX resistance of breast cancer cells by regulating the AKT pathway, promoting anti-apoptotic protein expression, and inhibiting pro-apoptotic protein expression, is upregulated in breast cancer [130]. Yang et al. found that the expression of circ-ABCB10 was upregulated in breast cancer cells. Circ-ABCB10 mediates the PTX resistance, apoptosis, invasion and autophagy of breast cancer cells through the let-7a-5p/DUSP7 axis [131].

\section{Prostate cancer}

CircFoxo3 can decrease the survival, migration, invasion, and docetaxel (DTX) resistance of prostate cancer cells and can influence DTX resistance through the circRNA/Foxo3/ EMT pathway [132]. Currently, androgen deprivation therapy (ADT) with enzalutamide (ENZ) can prolong the survival of patients with castration-resistant prostate cancer (CRPC). However, most patients develop ENZ resistance [133]. Hsa_circ_0004870 is downregulated in ENZ-resistant cells and plays a key role in mediating ENZ resistance in CRPC cells through RBM39 [134]. Another study showed that circRNA17 may suppress ENZ resistance in ENZresistant CRPC tumour cells by altering miR-181c-5p/ARv7 signalling [135].

\section{Gastric cancer}

CDDP, MTA, PTX, and oxaliplatin (OXA) are commonly used in gastric cancer (GC) chemotherapy [136-138]. However, patients always acquire chemotherapeutic resistance after treatment, which limits the overall clinical efficacy of the treatment. CircPVT1 is a carcinogenic factor in GC, mediating PTX resistance by upregulating ZEB1 via miR-124-3p [139]. Huang et al. found that circFN1 can promote CDDP-induced GC cell activity and inhibit GC cell apoptosis in vivo and in vitro. CircFN1 inhibits GC 


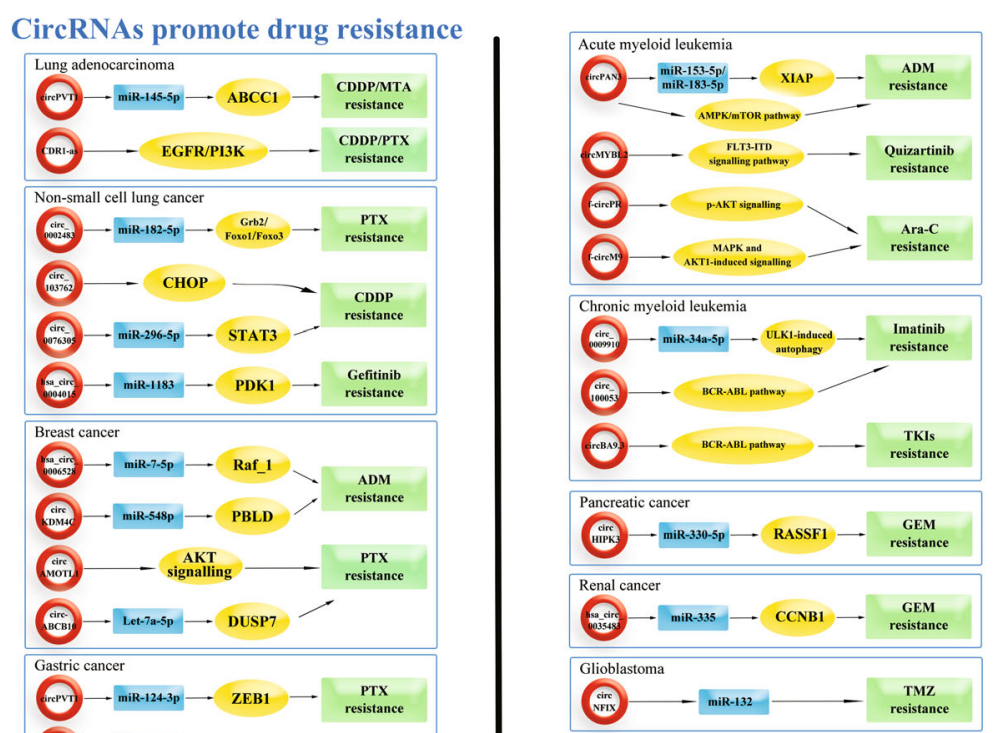

CircRNAs inhibite drug resistance

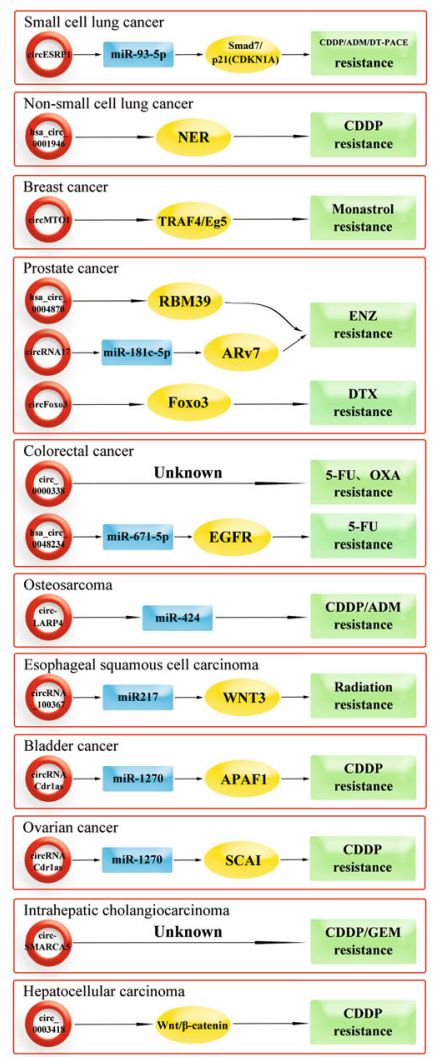

Fig. 3 The mechanisms of circRNAs in drug-resistant tumours. Circular RNAs are a double-edged sword in the mechanism of drug-resistant tumors, which can not only promote drug resistance but also inhibit drug resistance

cell apoptosis through sponging miR-182-5p and promotes CDDP resistance in GC, suggesting that circFN1 could be a therapeutic target in GC patients receiving CDDP treatment [106]. As another example of circRNA involvement in CDDP resistance in GC, circAKT3 can regulate phosphoinositide 3-kinase regulatory subunit 1 (PIK3R1), while PIK3R1 increases CDDP resistance by activating the PI3K/AKT signalling pathway [140]. Zhang et al. found that circCCDC66 is an important regulator of CDDP resistance and is highly expressed in CDDP- 
Table 2 Overview of circRNAs in drug-resistant tumors

\begin{tabular}{|c|c|c|c|c|c|c|}
\hline Cancer type & circRNAs & $\begin{array}{l}\text { Drug } \\
\text { resistance }\end{array}$ & Resistance mechanisms & Dysregulation & Biomarker & Refs \\
\hline \multirow[t]{2}{*}{ LUAD } & circPVT1 & CDDP/MTA & miR-145-5p/ABCC1 axis & Upregulated & Prognostic & [120] \\
\hline & CDR1-AS & PTX/CDDP & EGFR/PI3K signalling pathway & Upregulated & Prognostic & [105] \\
\hline $\mathrm{SCLC}$ & circESRP1 & $\begin{array}{l}\text { CDDP/ADM/ } \\
\text { DT-PACE }\end{array}$ & miR-93-5p/Smad7/p21(CDKN1A) & Downregulated & $\begin{array}{l}\text { Prognostic and } \\
\text { Therapeutic targets }\end{array}$ & [121] \\
\hline \multirow[t]{5}{*}{ NSCLC } & $\begin{array}{l}\text { circ__ } \\
0002483\end{array}$ & PTX & miR-182-5p/Grb2、Foxo1、Foxo3 & Downregulated & Therapeutic targets & [122] \\
\hline & $\begin{array}{l}\text { circ } \\
0076305\end{array}$ & CDDP & miR-296-5p/STAT3 & Upregulated & Therapeutic targets & [123] \\
\hline & $\begin{array}{l}\text { circRNA_ } \\
103762\end{array}$ & CDDP & $\mathrm{CHOP}$ & Upregulated & Therapeutic targets & [124] \\
\hline & $\begin{array}{l}\text { hsa_circ_- } \\
0001946\end{array}$ & CDDP & NER signalling pathway & Downregulated & $\begin{array}{l}\text { Diagnosis and } \\
\text { Prognostic }\end{array}$ & [125] \\
\hline & $\begin{array}{l}\text { hsa_circ_ } \\
0004015\end{array}$ & Gefitinib & miR1183-PDK1 axis & Upregulated & Therapeutic targets & {$[25]$} \\
\hline \multirow[t]{5}{*}{ Breast cancer } & $\begin{array}{l}\text { hsa_circ_- } \\
0006528\end{array}$ & ADM & miR-7-5p/Raf_1 axis & Upregulated & Unknown & [113] \\
\hline & circKDM4C & ADM & miR-548p/PBLD axis & Downregulated & Prognostic & [128] \\
\hline & circMTO1 & Monastrol & TRAF4/Eg5 pathway & Downregulated & $\begin{array}{l}\text { Prognostic and } \\
\text { Therapeutic targets }\end{array}$ & [129] \\
\hline & circAMOTL1 & PTX & AKT signalling pathway & Upregulated & Therapeutic targets & [130] \\
\hline & circ-ABCB10 & PTX & Let-7a-5p /DUSP7 axis & Upregulated & Therapeutic targets & [131] \\
\hline \multirow[t]{3}{*}{ Prostate cancer } & circFoxo3 & DTX & Foxo3 & Downregulated & $\begin{array}{l}\text { Prognostic and } \\
\text { Therapeutic targets }\end{array}$ & [132] \\
\hline & $\begin{array}{l}\text { hsa_circ_- } \\
0004870\end{array}$ & ENZ & RBM39 & Downregulated & $\begin{array}{l}\text { Diagnosis and } \\
\text { Prognostic }\end{array}$ & [134] \\
\hline & circRNA17 & ENZ & miR-181c-5p/ARv7 signalling pathway & Downregulated & Therapeutic targets & [135] \\
\hline \multirow[t]{7}{*}{ Gastric cancer } & circPVT1 & PTX & miR-124-3p/ZEB1 & Upregulated & Therapeutic targets & [139] \\
\hline & circFN1 & CDDP & miR-182-5p & Upregulated & Therapeutic targets & [106] \\
\hline & circAKT3 & CDDP & PI3KAKT signalling pathway & Upregulated & Therapeutic targets & [140] \\
\hline & circCCDC66 & CDDP & miR-618 and releasing BCL2 & Upregulated & Therapeutic targets & [136] \\
\hline & circMTHFD2 & MTA & miR-124/MDR-1 & Upregulated & Drug targets & [141] \\
\hline & circ0001546 & OXA & ATM/Chk2/p53 & Downregulated & $\begin{array}{l}\text { Diagnosis and } \\
\text { Prognostic }\end{array}$ & [115] \\
\hline & circRACGAP1 & Apatinib & miR-3657/ATG7 axis & Upregulated & Therapeutic targets & [142] \\
\hline \multirow[t]{6}{*}{ Colorectal cancer } & $\begin{array}{l}\text { circ } \\
0000338\end{array}$ & 5-FU/OXA & unknown & Upregulated & Drug targets & [143] \\
\hline & CIRS-122 & Apatinib & miR-122-PKM2 & Upregulated & Therapeutic targets & [144] \\
\hline & $\begin{array}{l}\text { hsa_circ_- } \\
0007031\end{array}$ & $5-\mathrm{FU}$ & miR-885-3p/AKT3 & Upregulated & Drug targets & [107] \\
\hline & $\begin{array}{l}\text { hsa_circ_- } \\
0000504\end{array}$ & $5-\mathrm{FU}$ & miR-485-5p/STAT3/AKT3 & Upregulated & Drug targets & [107] \\
\hline & $\begin{array}{l}\text { hsa_circ_- } \\
0048234\end{array}$ & $5-\mathrm{FU}$ & miR-671-5p/EGFR axis & Downregulated & Drug targets & [107] \\
\hline & $\begin{array}{l}\text { hsa_circ_ } \\
0079662\end{array}$ & OXA & hsa-miR-324-5p/ HOXA9/ TNF-a & Upregulated & Unknown & [145] \\
\hline \multirow[t]{2}{*}{ Osteosarcoma } & circPVT1 & $\mathrm{ADM} / \mathrm{CDDP}$ & unknown & Upregulated & $\begin{array}{l}\text { Diagnosis and } \\
\text { Prognostic }\end{array}$ & {$[24]$} \\
\hline & circ-LARP4 & $\mathrm{ADM} / \mathrm{CDDP}$ & $\operatorname{miR}-424$ & Downregulated & Unknown & [116] \\
\hline
\end{tabular}


Table 2 Overview of circRNAs in drug-resistant tumors (Continued)

\begin{tabular}{|c|c|c|c|c|c|c|}
\hline Cancer type & circRNAs & $\begin{array}{l}\text { Drug } \\
\text { resistance }\end{array}$ & Resistance mechanisms & Dysregulation & Biomarker & Refs \\
\hline & $\begin{array}{l}\text { hsa_circ } \\
001569\end{array}$ & CDDP & Wnt/ $\beta$-catenin signalling pathway & Upregulated & Therapeutic targets & [149] \\
\hline \multirow[t]{3}{*}{ ESCC } & $\begin{array}{l}\text { circRNA } \\
100367\end{array}$ & $\begin{array}{l}\text { Radiation } \\
\text { resistance }\end{array}$ & miR217/WNT3 & Upregulated & Therapeutic targets & [151] \\
\hline & CirclTCH & $\begin{array}{l}\text { Radiation } \\
\text { resistance }\end{array}$ & Wnt/ $\beta$ signalling pathway & Downregulated & Therapeutic targets & [152] \\
\hline & $\begin{array}{l}\text { circRNA } \\
001275\end{array}$ & CDDP & miR-370-3p/ Wnt7a & Upregulated & $\begin{array}{l}\text { Diagnosis and } \\
\text { Therapeutic targets }\end{array}$ & [153] \\
\hline Nasopharynx cancer & circCRIM1 & DTX & miR-422a/FOXQ1 & Upregulated & $\begin{array}{l}\text { Prognostic and } \\
\text { Therapeutic targets }\end{array}$ & [154] \\
\hline \multirow[t]{2}{*}{ Bladder cancer } & $\begin{array}{l}\text { hsa_circ_ } \\
0000285\end{array}$ & CDDP & miR-124 and miR-558 & Downregulated & Prognostic & [156] \\
\hline & $\begin{array}{l}\text { circRNA } \\
\text { Cdrlas }\end{array}$ & CDDP & miR-1270/APAF1 & Upregulated & Therapeutic targets & [157] \\
\hline \multirow[t]{2}{*}{ Ovarian cancer } & $\begin{array}{l}\text { circRNA } \\
\text { Cdr1as }\end{array}$ & CDDP & miR-1270/SCAl & Downregulated & Unknown & [158] \\
\hline & circCELSR1 & PTX & miR-1252/FOXR2 & Upregulated & Therapeutic targets & [159] \\
\hline \multirow[t]{4}{*}{ AML } & circPAN3 & ADM & $\begin{array}{l}\text { circPAN3-miR-153-5p/miR-183-5p-XIAP axis or } \\
\text { AMPK/mTOR pathway }\end{array}$ & Upregulated & Drug targets & $\begin{array}{l}{[161,} \\
162]\end{array}$ \\
\hline & circMYBL2 & quizartinib & FLT3-ITD signalling pathway & Upregulated & Therapeutic targets & {$[82]$} \\
\hline & f-circPR & Ara-C & p-AKT signalling & Upregulated & $\begin{array}{l}\text { Diagnosis and } \\
\text { Therapeutic targets }\end{array}$ & {$[36]$} \\
\hline & f-circM9 & Ara-C & MAPK and AKT1-induced signalling & Upregulated & $\begin{array}{l}\text { Diagnosis and } \\
\text { Therapeutic targets }\end{array}$ & {$[36]$} \\
\hline \multirow[t]{3}{*}{ CML } & $\begin{array}{l}\text { circ__ } \\
0009910\end{array}$ & imatinib & miR-34a-5p/ ULK1-induced autophagy & Upregulated & Drug targets & [165] \\
\hline & $\operatorname{circBA9.3}$ & TKls & BCR-ABL pathway & Upregulated & Therapeutic targets & [166] \\
\hline & circ_100053 & imatinib & BCR-ABL pathway & Upregulated & $\begin{array}{l}\text { Diagnosis and } \\
\text { Therapeutic targets }\end{array}$ & [168] \\
\hline MM & $\begin{array}{l}\text { hsa_circ_ } \\
0007841\end{array}$ & BTZ & unknown & Upregulated & $\begin{array}{l}\text { Diagnosis and } \\
\text { Prognostic }\end{array}$ & [170] \\
\hline Pancreatic cancer & circHIPK3 & GEM & miR-330-5p/RASSF1 & Upregulated & $\begin{array}{l}\text { Prognostic and Drug } \\
\text { targets }\end{array}$ & [171] \\
\hline Cholangiocarcinoma & $\begin{array}{l}\text { circ- } \\
\text { SMARCA5 }\end{array}$ & CDDP/GEM & unknown & Downregulated & Prognostic & [172] \\
\hline $\mathrm{HCC}$ & $\begin{array}{l}\text { circ } \\
0003418\end{array}$ & CDDP & Wnt/ß-catenin signaling pathway & Downregulated & Unknown & [173] \\
\hline Renal carcinoma & $\begin{array}{l}\text { hsa_circ_ } \\
0035483\end{array}$ & GEM & miR-335/CCNB1 & Upregulated & Unknown & [174] \\
\hline Glioblastoma & circNFIX & $\mathrm{TMZ}$ & miR-132 & Upregulated & $\begin{array}{l}\text { Prognostic and } \\
\text { Therapeutic targets }\end{array}$ & [175] \\
\hline
\end{tabular}

resistant cells and tissues. In vitro and in vivo experiments showed that circCCDC66 inhibits apoptosis and promotes drug resistance by targeting miR-618 and releasing B cell lymphoma-2 (BCL2) [136]. Via microarray analysis, Xu et al. identified the upregulation of circMTHFD2, which bound directly to miR-124 as a molecular sponge, in GC cells. This binding induced an increase in MDR-1 protein expression, ultimately enhancing MTA resistance in GC cells [141]. Circ_0001546 is upregulated in GC tissues and cells, which can increase ATM expression and inhibit cell proliferation and OXA resistance by activating the ATM/ Chk2/p53-dependent pathway [115]. In GC cells, silencing circRACGAP1 inhibits apatinib-induced autophagy, which can be rescued by miR-3657 expression. Knockout of the circRACGAP1 gene endows GC cells with sensitivity to apatinib by inhibiting autophagy. CircRACGAP1 was found to mediate apatinib resistance through the circRACGAP1/miR-3657/ATG7 axis [142]. 


\section{Colorectal cancer}

Hon et al. found that circ_0000338 has a tumoursuppressive effect in colorectal cancer and can enhance the chemosensitivity of colorectal cancer cells. Knockout of hsa_circ_0000338 in HCT116-R cells increases 5fluorouracil (5-FU) and OXA resistance and may have a dual regulatory effect. Hsa_circ_0000338 was selectively transfected into $\mathrm{HCT}_{-} 116-\mathrm{P}$ cells cocultured with $\mathrm{HCT}_{-}$ $116-\mathrm{R}$ exosomes, which exhibited a more robust response to drug therapy than control cells. Hsa_circ 0000338 may play a carcinogenic role in HCT116-R exosomes and enhance the drug resistance of the recipient cells [143]. In addition, CIRS-122 (hsa_circ_0005963) acts as a sponge for miR-122, which targets PKM_2, and is positively correlated with chemotherapeutic resistance. Studies have shown that exosomes from OXA-resistant cells transport CIRS-122 to sensitive cells, thereby promoting glycolysis and chemotherapeutic resistance through upregulation of miR-122 sponging and PKM2 expression. In addition, extracellular transport of siCIRC-122 inhibits glycolysis and reverses OXA resistance in vivo by regulating the CIRS-122/miR-122/PKM2 pathway [144]. Xiong et al. investigated circRNA regulation in 5-FU-resistant colorectal cancer cells for the first time, finding that the most strongly upregulated circRNAs-hsa_circ_0007031 and hsa_circ_0000504-promoted 5-FU resistance by regulating the circRNA/miR853-3p/AKT3 and circRNA/miR-485-5p/STAT3/AKT3 signalling pathways or by regulating $\mathrm{Bcl} 2$ protein expression. In addition, the authors speculated that downregulation of hsa_circ_0048234, which has four miR-671-5p binding sites, may promote drug resistance by upregulating the miR-671-5p/EGFR axis [107]. Lai et al. found that hsa_circ_0079662, which can bind to hsa-miR-324-5p, regulate the target gene HOXA9, and induce resistance to the chemotherapeutic drug OXA in colorectal cancer via the tumor necrosis factor- $\alpha$ (TNF- $\alpha$ ) pathway, is upregulated in drug-resistant colorectal cancer cells [145].

\section{Osteosarcoma}

Osteosarcoma (OS) is one of the most common primary bone tumours. CircPVT1 is significantly upregulated in OS and can reduce the resistance of OS cells to ADM and CDDP by decreasing the expression of the ABCB1 gene, which is related to classical drug resistance, after knockout [24]. However, the detailed mechanism is unclear. Overexpression of circ-LARP4 increases the sensitivity of MG63 cells to CDDP and ADM but does not significantly affect sensitivity to methotrexate (MTX). In addition, overexpression of miR-424 reduces the chemosensitivity of circ-LARP4-overexpressing MG63 cells [116]. In addition, experimental results have shown that circ-LARP4 can affect the development of GC [146], ovarian tumours [147], and oesophageal squamous cell carcinoma (ESCC) [148]. Zhang et al. found that hsa_circ 001569 is upregulated in CDDP-resistant OS cells, which promotes cell proliferation by activating the Wnt/ $\beta$-catenin pathway and enhances resistance to CDDP [149].

\section{Oesophageal squamous cell carcinoma}

Radiotherapy is a main treatment for patients with ESCC. However, radioresistance is a historical reason for the failure of ESCC therapy and local tumour recurrence [150]. In ESCC, circRNA_100367 attenuates the radioresistance of oesophageal tumour cells via the miR217/Wnt3 pathway. CircRNA_100367 inhibits the proliferation and migration of ESCC cells [151]. In addition, circITCH is downregulated in ESCC tissues. As previous radioresistance studies indicated, circITCH may inhibit the expression of its target gene by inhibiting the Wnt/ $\beta$-catenin signalling pathway, thus affecting radioresistance in ESCC [152]. CircRNA_001275 is significantly upregulated in CDDPresistant oesophageal cancer tissues and cells. Overexpression of circRNA_001275 promotes the proliferation and invasion of CDDP-resistant cells, reduces their apoptosis, and promotes CDDP resistance by upregulating Wnt7a expression by sponging miR-3703p [153].

\section{Nasopharyngeal carcinoma}

In highly metastatic nasopharyngeal carcinoma (NPC) cells, circCRIM1 is upregulated. Overexpression of circCRIM1 promotes NPC cell metastasis and EMT. CircCRIM1 can competitively bind miR-422a and block the inhibitory effect of miR-422a on its target gene FOXQ1, resulting in metastasis, EMT, and DTX resistance in NPC [154]. Additionally, upregulation of circCRIM1 is associated with poor survival of NPC patients. Via the development of a prognostic model based on circCRIM1 expression and $\mathrm{N}$ staging, the risk of distant metastasis and the therapeutic response to DTX-induced chemotherapy in NPC patients can be effectively predicted.

\section{Bladder cancer and ovarian cancer}

Bladder cancer is a common tumour of the urinary system. Most (75-80\%) bladder cancer patients receive transurethral resection; however, those with advanced bladder cancer can receive only chemotherapy or radiotherapy [155]. However, due to chemotherapeutic resistance, some patients do not benefit from this treatment. Chi et al. studied the differential expression of circRNAs in bladder cancer cell lines and found that the expression of hsa_circ_0000285 in CDDP-resistant cells is almost three times that in CDDP-sensitive cells. The possible mechanism underlying this difference may be related to the expression of miR-124 and miR-558 [156]. 
Another study showed that circCdr1as sensitizes bladder cancer cells to CDDP by restoring the expression of APAF1, which is decreased by miR-1270. APAF1 silencing decreased the sensitivity of bladder cancer cells to CDDP [157]. In addition, in ovarian cancer, circCdr1as reduces CDDP resistance by inhibiting miR-1270 and upregulating SCAI. Similarly, overexpression of Cdr1as inhibits the proliferation of ovarian cancer cells and promotes CDDP-induced apoptosis [158]. CircRNAs are currently considered essential regulators of tumour development and progression. Zhang et al., through gene chip analysis, found that circCELSR1 (hsa_circ_0063809) is upregulated in PTX-resistant ovarian cancer tissues and cells. CircCELSR1 regulates the expression of FOXR2 via miR-1252 and mediates the resistance of ovarian cancer cells to PTX [159]. Silencing of circCELSR1 enhances the cytotoxic effect of PTX in ovarian cancer cells.

\section{Acute myeloid leukaemia}

Acute myeloid leukaemia (AML) is a highly heterogeneous haematologic malignancy. Drug resistance and recurrence are the key factors in the failure of leukaemia treatment [160]. Shang et al. found that circPAN3, which may be a key regulatory factor for acquired chemoresistance in AML, is upregulated in drug-resistant AML cells and mediates ADM resistance through different pathways. Autophagy can be regulated through the circPAN3-miR-153-5p/miR-183-5p-XIAP axis or the AMPK/mTOR pathway, which act as autophagy inducers, to promote ADM resistance in AML cells [161, 162]. Sun et al. found that circMYBL2 expression is higher in AML patients with FLT3-ITD mutations than in AML patients without FLT3-ITD mutations. Knockout of the circMYBL2 gene specifically inhibits the proliferation of FLT3-ITD+ AML cells and overcomes acquired resistance to quizartinib [82]. In addition, Guarnerio et al. discovered a new class of circRNAs, fcircRNAs [36]. This type of circRNA was later identified in the MiOncoCirc database [37]. F-circRNAs cannot trigger tumorigenesis alone, but in combination with other carcinogenic stimuli, they can promote the development of leukaemia and acquired drug resistance. Expression of both f-circPR and f-circM9 leads to an increase in cell proliferation and transformation, but $\mathrm{f}$ circM9 can trigger both mitogen-activated protein kinase (MAPK) and AKT1 signalling, thereby affecting drug resistance. In the presence of $\mathrm{f}$-circPR, the $\mathrm{p}$-AKT level is increased only slightly but affects drug resistance [36].

\section{Chronic myeloid leukaemia}

Chronic myeloid leukaemia (CML) is a disorder of uncontrolled myeloid stem cell proliferation characterized by the Philadelphia chromosome [163]. The development of imatinib and other tyrosine kinase inhibitors (TKIs) has altered the course of the disease; however, resistance develops in approximately $13 \%$ of patients [164]. Circ_ 0009910, which can regulate ULK1-induced autophagy by targeting miR-34a-5p and accelerate the development of imatinib resistance in CML cells, is upregulated in the serum and cells of imatinib-resistant CML patients [165]. In addition, circBA9.3, a circRNA derived from BCR$\mathrm{ABL} 1$, can promote cell proliferation by upregulating the protein expression levels of $\mathrm{c}-\mathrm{ABL} 1$ and BCR-ABL1 and make CML cells resistant to TKIs, including imatinib, nilotinib, and dasatinib [166]. Ping et al. found that the expression of circ_100053 in imatinib-resistant CML patients is higher than that in imatinib-sensitive patients. Mutations in the BCR-ABL kinase domain (KD) often lead to imatinib resistance [167]. Thus, circ_100053 may regulate imatinib resistance by regulating the $\mathrm{BCR}-\mathrm{ABL}$ pathway [168].

\section{Multiple myeloma}

Multiple myeloma (MM) is a haematologic malignancy caused by abnormal proliferation of bone marrow plasma cells. Although new treatments have greatly improved the prognosis of MM, its incidence has been increasing annually. A main factor contributing to this phenomenon is the high heterogeneity of MM cells, which leads to disease recurrence and drug resistance in patients [169]. Gao et al. found that the expression of hsa_circ_0007841 is significantly upregulated in MM cell lines and bortezomib (BTZ)-resistant cell lines and that the hsa_circ_0007841 expression level is significantly higher in MM patients with BTZ resistance than in MM patients with BTZ sensitivity. Therefore, upregulation of hsa_circ_0007841 may be involved in BTZ tolerance in MM patients [170].

\section{Other cancers}

CircRNAs also play an essential role in drug resistance in other tumours. CircHIPK3 is upregulated in gemcitabine (GEM)-resistant pancreatic cancer cells. Experiments proved that circHIPK3 targets RASSF1 through miR-330-5p, promotes GEM resistance in pancreatic cancer cells, and regulates cell proliferation, invasion, migration, EMT, and apoptosis [171]. In addition, in cholangiocarcinoma, downregulation of circ_SMARCA5 inhibits the proliferation of CDDP- and GEM-treated cells, reduces the relative cell survival rate, and reduces the inhibitory concentration (IC) of CDDP and GEM by $50 \%$. Circ_SMARCA5 has potential application value in monitoring disease progression and predicting prognosis in intrahepatic cholangiocarcinoma (ICC) [172]. Circ_ 0003418 is downregulated in hepatocellular carcinoma (HCC) tissues and cell lines and is associated with the tumour size, TNM stage, and HBsAg level. Inhibition of 
circ_0003418 enhances the CDDP resistance of HCC cells in vivo and in vitro. Circ_0003418 gene knockout activates the $\mathrm{Wnt} / \beta$-catenin signalling pathway in $\mathrm{HCC}$ cells. However, after inhibition of the $\mathrm{Wnt} / \beta$-catenin pathway, the effect of circ-0003418 on the CDDP sensitivity of hepatoma cells was reversed [173]. In renal cancer, hsa_circ_0035483 promotes autophagy and tumour growth by regulating the miR-335/CCNB1 axis and enhances GEM resistance, and silencing hsa_circ_0035483 can enhance GEM sensitivity [174]. Another study showed that exosomal CircNFIX is upregulated in the serum of temozolomide (TMZ)-resistant patients. CircNFIX can interact directly with miR-132 and enhance the TMZ sensitivity of drug-resistant glioma cells as well as promote cell migration and invasion and inhibit apoptosis [175].

\section{Conclusions}

With the development of modern medicine, tumour treatment is progressing from a traditional treatment model to a targeted treatment model. Targeted therapy can specifically kill tumour cells without affecting the normal peritumoral cells. To date, numerous drugs have been developed for targeted therapy. For example, targeted drugs for GC include PTX, CDDP, MTA, OXA, and apatinib; targeted drugs for colorectal cancer include 5-FU and OXA; and targeted drugs for pancreatic tumours include GEM. However, clinically, tumour cells gradually develop resistance to targeted drugs.

CircRNAs are widely distributed in eukaryotic cells and have a long half-life. Moreover, the expression levels of circRNAs are tissue- and developmental stagespecific. Therefore, we believe that circRNAs have potential as tumour markers and therapeutic targets. However, we found that circRNAs act as a double-edged sword in chemoresistance, not only promoting but also suppressing drug resistance. CircPVT1 promotes CDDP and MTA resistance in LUAD by targeting miR-145-5p and increasing the chemosensitivity of tumour cells. In contrast, monastrol resistance can be reversed in breast cancer via the TRAF4/Eg5 pathway through overexpression of circMTO1. CircRNAs also have a dual regulatory effect in some tumour chemoresistance mechanisms. For example, hsa_circ_0000338 in tumour cells can inhibit tumour growth, but exosomal hsa_circ_0000338 has a carcinogenic effect.

CircRNAs play an essential role in chemoresistance, but the mechanism is not entirely clear. Hidden mechanisms of resistance will lead us to recognize the importance of circRNAs in human tumours. With continuous improvements in circRNA databases and detection technology, we believe that circRNAs will be applied clinically and provide a new approach for tumour treatment.

\section{Abbreviations}

CircRNAs: Circular RNAs; ncRNA: Non-coding RNA; RNase R: Ribonuclease R; miRNAs: microRNAs; RBPs: RNA-binding proteins; IncRNA: Long non-coding RNA; EciRNAs: Exon circRNAs; ElciRNAs: Exon-intron circRNAs; CiRNAs: Intronic circRNAs; pre-mRNA: Premessenger RNA; f-circRNAs: Fusion-circRNAs; rtcircRNAs: Read-through circRNAs; UTR: Untranslated Regions;

MIR: Mammalian-Wide Interspersed Repeats; $\mathrm{m}^{6} \mathrm{~A}$ : $\mathrm{N}^{6}$-methyladinosinek; ORF: Open Reading Frame; RIP: RNA Binding Protein Immunoprecipitation; QKI: Quaking; FUS: Fused in sarcoma; SRSF3: Serine/arginine-rich splicing factor 3; hnRNPs: Heterogeneous nuclear ribonucleoproteins; DHX9: ATPdependent RNA helicase A; ILF3: Interleukin Enhancer Binding Factor 3; AGO2: Argonaute 2; RNAi: RNA interference; YTHDF2: YTH domain-containing family protein 2; HRSP12: Heat- responsive protein 12; RNase P: Ribonuclease P; PKR: Double-stranded RNA-activated protein kinase; RNase L: Ribonuclease L; SRD: Structure-Mediated RNA Decay; YTHDC1: YTH domain-containing family protein 1; FISH: Fluorescence in situ hybridization; LUAD: Lung adenocarcinoma; CDK6: Cyclin-dependent kinase 6; TFF1: Trefoil factor 1; ceRNAs: Competing endogenous RNAs; EMT: Epithelial mesenchymal transition; NSCLC: Non-small-cell lung cancer; Tgf- $\beta 2$ : Transforming growth factor- $\beta 2$; PCa: Prostatic tumor; PDAC: Pancreatic ductal adenocarcinoma; MBL: Muscle-blind; RNA Pol II: RNA polymerase II; U1 snRNP: U1 small nuclear ribonucleoprotein; PDK1: 3-phosphoinositide- dependent protein kinase 1; IRES: Internal ribosome entry site; PDAC: Pancreatic ductal adenocarcinoma; RCA: Roll ring amplification; CDDP: Cisplatin; MTA: Pemetrexed;

PTX: Paclitaxel; SCLC: Small cell lung cancer; p21: Cyclin-dependent kinase inhibitor 1; EGFR: Epidermal Growth Factor Receptor;

PI3K: Phosphatidylinositol 3-kinase; Grb2: Growth factor receptor-bound protein2;Foxo1forkheadboxclass1; Foxo 3: Forkheadboxclass 3; ADM: Adriamycin; TRAF4: TNF receptor-associated factor 4; DTX: Docetaxel; ADT: Androgen deprivation therapy; CRPC: Castration resistant prostate cancer;

ENZ: Enzalutamide; OXA: Oxaliplatin; GC: Gastric cancer;

PIK3R1: Phosphoinositide-3-Kinase Regulatory Subunit 1; BCL2: B cell lymphoma-2; CRC: Colorectal cancer; 5-FU: 5-fluorocrail; TNF-a: Tumor necrosis factor-a; OS: Osteosarcoma; MTX: Methotrexate; ESCC: Esophageal squamous cell carcinoma; NPC: Nasopharyngeal carcinoma; AML: Acute myeloid leukemia; FLT3: FMS-like tyrosine kinase-3; ITD: tandem repeat; MAPK: Mitogen-activated protein kinase; CML: Chronic myeloid leukemia; TKls: Tyrosine kinase inhibitors; KD: Kinase domain; MM: Multiple myeloma; BTZ: Bortezomib; GEM: Gemcitabine; ICC: Intrahepatic cholangiocarcinoma; TNM: Tumor Node Metastasis; TMZ: Temozolomide; DT-PACE: Etoposide

\section{Acknowledgements}

Not applicable.

\section{Authors' contributions}

S.M. collected the related paper and drafted the manuscript. S.K. revised the manuscript. S.J. and F.W. participated in the design of the review and helped to draft and modify the manuscript. All authors read and approved the final manuscript.

\section{Funding}

This project was supported by grants from the National Natural Science Foundation of China [grant number: 81871720, 81873978], Jiangsu Program for Young Medical Talents [grant number: QNRC2016689, QNRC2016695], Social Development Key Project in Jiangsu Province [grant number: BE2019691], Sixth Talent Peaks Project of Jiangsu Province [grant number: 2018-WSW-068], Chinese Post-doctoral Science Foundation [grant number: 2018 M642298], and Jiangsu Innovation and Entrepreneurship Training Program for Undergraduates [grant number: 201810304076Y].

\section{Availability of data and materials}

Not applicable.

Ethics approval and consent to participate Not applicable.

\section{Consent for publication}

All authors have read and approved the final manuscript.

\section{Competing interests}

The authors declare that they have no competing interests. 


\section{Author details}

${ }^{1}$ Department of Laboratory Medicine, Affiliated Hospital of Nantong University, NO.20, Xisi Road, Nantong 226001, Jiangsu, China. ${ }^{2}$ Research Center of Clinical Medicine, Affiliated Hospital of Nantong University, NO.20, Xisi Road, Nantong 226001, Jiangsu, China. ${ }^{3}$ School of Public Health, Nantong University, NO. 9, Seyuan Road, Nantong 226019, Jiangsu, China.

\section{Received: 8 April 2020 Accepted: 3 July 2020}

\section{Published online: 05 August 2020}

\section{References}

1. Ashwal-Fluss R, Meyer M, Pamudurti NR, Ivanov A, Bartok O, Hanan M, Evantal N, Memczak S, Rajewsky N, Kadener S. circRNA biogenesis competes with pre-mRNA splicing. Mol Cell. 2014;56:55-66.

2. Sanger HL, Klotz G, Riesner D, Gross HJ, Kleinschmidt AK. Viroids are singlestranded covalently closed circular RNA molecules existing as highly basepaired rod-like structures. Proc Natl Acad Sci U S A. 1976;73:3852-6.

3. Memczak S, Jens M, Elefsinioti A, Torti F, Krueger J, Rybak A, Maier L, Mackowiak SD, Gregersen LH, Munschauer M, et al. Circular RNAs are a large class of animal RNAs with regulatory potency. Nature. 2013;495:333-8.

4. Barrett SP, Salzman J. Circular RNAs: analysis, expression and potential functions. Development. 2016;143:1838-47.

5. Rybak-Wolf A, Stottmeister C, Glažar P, Jens M, Pino N, Giusti S, Hanan M, Behm M, Bartok O, Ashwal-Fluss R, et al. Circular RNAs in the mammalian brain are highly abundant, conserved, and dynamically expressed. Mol Cell. 2015:58:870-85.

6. Wang PL, Bao Y, Yee MC, Barrett SP, Hogan GJ, Olsen MN, Dinneny JR, Brown PO, Salzman J. Circular RNA is expressed across the eukaryotic tree of life. PLoS One. 2014;9:e90859.

7. Ivanov A, Memczak S, Wyler E, Torti F, Porath HT, Orejuela MR, Piechotta M, Levanon EY, Landthaler M, Dieterich C, Rajewsky N. Analysis of intron sequences reveals hallmarks of circular RNA biogenesis in animals. Cell Rep. 2015:10:170-7.

8. Westholm JO, Miura P, Olson S, Shenker S, Joseph B, Sanfilippo P, Celniker SE, Graveley BR, Lai EC. Genome-wide analysis of drosophila circular RNAs reveals their structural and sequence properties and age-dependent neural accumulation. Cell Rep. 2014;9:1966-80.

9. Jeck WR, Sorrentino JA, Wang K, Slevin MK, Burd CE, Liu J, Marzluff WF, Sharpless NE. Circular RNAs are abundant, conserved, and associated with ALU repeats. RNA. 2013;19:141-57.

10. Salzman J, Gawad C, Wang PL, Lacayo N, Brown PO. Circular RNAs are the predominant transcript isoform from hundreds of human genes in diverse cell types. PLoS One. 2012;7:e30733.

11. Chen LL, Yang L. Regulation of circRNA biogenesis. RNA Biol. 2015;12:381-8.

12. Dong R, Ma XK, Chen LL, Yang L. Increased complexity of circRNA expression during species evolution. RNA Biol. 2017;14:1064-74.

13. Salzman J, Chen RE, Olsen MN, Wang PL, Brown PO. Cell-type specific features of circular RNA expression. PLoS Genet. 2013;9:e1003777.

14. Nicolet BP, Engels S, Aglialoro F, van den Akker E, von Lindern M, Wolkers MC. Circular RNA expression in human hematopoietic cells is widespread and cell-type specific. Nucleic Acids Res. 2018;46:8168-80.

15. Zhang P, Zuo Z, Shang W, Wu A, Bi R, Wu J, Li S, Sun X, Jiang L. Identification of differentially expressed circular RNAs in human colorectal cancer. Tumour Biol. 2017;39:1010428317694546.

16. Smid M, Wilting SM, Uhr K, Rodríguez-González FG, de Weerd V, der Smissen WJCP-V, van der Vlugt-Daane M, van Galen A, Nik-Zainal S, Butler A, et al. The circular RNome of primary breast cancer. Genome Res. 2019;29: 356-66.

17. Hansen $\mathrm{TB}$, Jensen $\mathrm{TI}$, Clausen BH, Bramsen JB, Finsen B, Damgaard CK, Kjems J. Natural RNA circles function as efficient microRNA sponges. Nature. 2013;495:384-8.

18. Kristensen LS, Andersen MS, Stagsted LWW, Ebbesen KK, Hansen TB, Kjems J. The biogenesis, biology and characterization of circular RNAs. Nat Rev Genet. 2019;20:675-91.

19. Liu C, Yao MD, Li CP, Shan K, Yang H, Wang JJ, Liu B, Li XM, Yao J, Jiang Q, Yan B. Silencing of circular RNA-ZNF609 ameliorates vascular endothelial dysfunction. Theranostics. 2017;7:2863-77.

20. Zeng Y, Du WW, Wu Y, Yang Z, Awan FM, Li X, Yang W, Zhang C, Yang Q, Yee A, et al. A circular RNA binds to and activates AKT phosphorylation and nuclear localization reducing apoptosis and enhancing cardiac repair. Theranostics. 2017;7:3842-55.
21. Zheng X, Chen L, Zhou Y, Wang Q, Zheng Z, Xu B, Wu C, Zhou Q, Hu W, Wu C, Jiang J. A novel protein encoded by a circular RNA circPPP1R12A promotes tumor pathogenesis and metastasis of colon cancer via hippoYAP signaling. Mol Cancer. 2019;18:47.

22. Ye L, Zhang Q, Cheng Y, Chen X, Wang G, Shi M, Zhang T, Cao Y, Pan H, Zhang L, et al. Tumor-derived exosomal HMGB1 fosters hepatocellular carcinoma immune evasion by promoting TIM-1 regulatory B cell expansion. J Immunother Cancer. 2018:6:145.

23. Legnini I, Di Timoteo G, Rossi F, Morlando M, Briganti F, Sthandier O, Fatica A, Santini T, Andronache A, Wade M, et al. Circ-ZNF609 Is a Circular RNA that Can Be Translated and Functions in Myogenesis. Mol Cell. 2017;66:22-37.e29.

24. Kun-Peng Z, Xiao-long M, Chun-Lin Z. Overexpressed circPVT1, a potential new circular RNA biomarker, contributes to doxorubicin and cisplatin resistance of osteosarcoma cells by regulating ABCB1. Int J Biol Sci. 2018;14:321-30.

25. Zhou Y, Zheng X, Xu B, Chen L, Wang Q, Deng H, Jiang J. Circular RNA hsa_ circ_0004015 regulates the proliferation, invasion, and TKI drug resistance of non-small cell lung cancer by miR-1183/PDPK1 signaling pathway. Biochem Biophys Res Commun. 2019;508:527-35.

26. Liu F, Zhang J, Qin L, Yang Z, Xiong J, Zhang Y, Li R, Li S, Wang H, Yu B, et al. circular RNA EIF6 (Hsa_circ_0060060) sponges miR-144-3p to promote the cisplatin-resistance of human thyroid carcinoma cells by autophagy regulation. Aging. 2018;10:3806-20.

27. Wu Y, Chen X, Wang S, Wang S. Advances in the relationship between glycosyltransferases and multidrug resistance in cancer. Clin Chim Acta. 2019:495:417-21.

28. Longley DB, Johnston PG. Molecular mechanisms of drug resistance. J Pathol. 2005;205:275-92.

29. Gao Q, Li XX, Xu YM, Zhang JZ, Rong SD, Qin YQ, Fang J. IRE1a-targeting downregulates $A B C$ transporters and overcomes drug resistance of colon cancer cells. Cancer Lett. 2020;476:67-74.

30. Ayers D. J Vandesompele: influence of microRNAs and long non-coding RNAs in Cancer Chemoresistance. Genes. 2017;8.

31. Starke S, Jost I, Rossbach O, Schneider T, Schreiner S, Hung LH. A Bindereif: exon circularization requires canonical splice signals. Cell Rep. 2015;10:103-11.

32. Zhang $Y$, Zhang XO, Chen T, Xiang JF, Yin QF, Xing YH, Zhu S, Yang L, Chen LL. Circular intronic long noncoding RNAs. Mol Cell. 2013;51:792-806.

33. Kelly S, Greenman C, Cook PR, Papantonis A. Exon skipping is correlated with exon circularization. J Mol Biol. 2015:427:2414-7.

34. Eger N, Schoppe L, Schuster S, Laufs U, Boeckel JN. Circular RNA splicing. Adv Exp Med Biol. 2018;1087:41-52.

35. Chen LL. The biogenesis and emerging roles of circular RNAs. Nat Rev Mol Cell Biol. 2016;17:205-11.

36. Guarnerio J, Bezzi M, Jeong JC, Paffenholz SV, Berry K, Naldini MM, Lo-Coco F, Tay $Y$, Beck AH, Pandolfi PP. Oncogenic role of fusion-circRNAs derived from Cancer-associated chromosomal translocations. Cell. 2016;166:1055-6.

37. Vo JN, Cieslik M, Zhang Y, Shukla S, Xiao L, Zhang Y, Wu YM, Dhanasekaran SM, Engelke CG, Cao X, et al. The Landscape of Circular RNA in Cancer. Cell. 2019;176:869-881.e813.

38. Lasda E, Parker R. Circular RNAs: diversity of form and function. RNA. 2014; 20:1829-42.

39. Yoshimoto R, Karim R, Thomas H, Jørgen K, Akila M. Biosynthesis of Circular RNA ciRS-7/CDR1as Is Mediated by Mammalian-Wide Interspersed Repeats (MIRs). bioRxiv. 2019:411231 https://doi.org/10.1101/411231.

40. Tang C, Xie Y, Yu T, Liu N, Wang Z, Woolsey RJ, Tang Y, Zhang X, Qin W, Zhang $Y$, et al. $m A$-dependent biogenesis of circular RNAs in male germ cells. Cell Res. 2020;30:211-28.

41. Di Timoteo G, Dattilo D, Centrón-Broco A, Colantoni A, Guarnacci M, Rossi F, Incarnato D, Oliviero S, Fatica A, Morlando M, Bozzoni I. Modulation of circRNA Metabolism by mA Modification. Cell Rep. 2020;31:107641.

42. Zhang XO, Wang HB, Zhang Y, Lu X, Chen LL, Yang L. Complementary sequence-mediated exon circularization. Cell. 2014;159:134-47.

43. Conn SJ, Pillman KA, Toubia J, Conn VM, Salmanidis M, Phillips CA, Roslan S, Schreiber AW, Gregory PA, Goodall GJ. The RNA binding protein quaking regulates formation of circRNAs. Cell. 2015;160:1125-34.

44. Errichelli L, Modigliani SD, Laneve P, Colantoni A, Legnini I, Capauto D, Rosa A, De Santis R, Scarfò R, Peruzzi G, et al. FUS affects circular RNA expression in murine embryonic stem cell-derived motor neurons. Nat Commun. 2017; 8:14741.

45. Ammar S, Naqvi AM, Black Kathryn L, Hayer Katharina E, Deanne T, Andrei T-T. The role of SRSF3 splicing factor in generating circular RNAs. bioRxiv. 2019: 799700 https://doi.org/10.1101/799700. 
46. Liang D, Tatomer DC, Luo Z, Wu H, Yang L, Chen LL, Cherry S, Wilusz JE. The Output of Protein-Coding Genes Shifts to Circular RNAs When the Pre-mRNA Processing Machinery Is Limiting. Mol Cell. 2017;68:940954.e943.

47. Aktaş T, Ilık IA, Maticzka D, Bhardwaj V, Rodrigues CP, Mittler G, Manke T, Backofen R, Akhtar A. DHX9 suppresses RNA processing defects originating from the Alu invasion of the human genome. Nature. 2017; 544:115-9.

48. Li X, Liu CX, Xue W, Zhang Y, Jiang S, Yin QF, Wei J, Yao RW, Yang L, Chen LL. Coordinated circRNA Biogenesis and Function with NF90/NF110 in Viral Infection. Mol Cell. 2017;67:214-227.e217.

49. Chen S, Huang V, Xu X, Livingstone J, Soares F, Jeon J, Zeng Y, Hua JT, Petricca J, Guo H, et al. Widespread and Functional RNA Circularization in Localized Prostate Cancer. Cell. 2019;176:831-843.e822.

50. Gruner H, Cortés-López M, Cooper DA, Bauer M, Miura P. CircRNA accumulation in the aging mouse brain. Sci Rep. 2016;6:38907.

51. Suzuki H, Zuo Y, Wang J, Zhang MQ, Malhotra A, Mayeda A. Characterization of RNase R-digested cellular RNA source that consists of lariat and circular RNAs from pre-mRNA splicing. Nucleic Acids Res. 2006;34:e63.

52. Enuka Y, Lauriola M, Feldman ME, Sas-Chen A, Ulitsky I, Yarden Y. Circular RNAs are long-lived and display only minimal early alterations in response to a growth factor. Nucleic Acids Res. 2016;44:1370-83.

53. Bachmayr-Heyda A, Reiner AT, Auer K, Sukhbaatar N, Aust S, BachleitnerHofmann T, Mesteri I, Grunt TW, Zeillinger R, Pils D. Correlation of circular RNA abundance with proliferation--exemplified with colorectal and ovarian cancer, idiopathic lung fibrosis, and normal human tissues. Sci Rep. 2015;5:8057.

54. Hansen TB, Wiklund ED, Bramsen JB, Villadsen SB, Statham AL, Clark SJ, Kjems J. miRNA-dependent gene silencing involving Ago2-mediated cleavage of a circular antisense RNA. EMBO J. 2011;30:4414-22.

55. Kleaveland B, Shi CY, Stefano J, Bartel DP. A Network of Noncoding Regulatory RNAs Acts in the Mammalian Brain. Cell. 2018;174:350-362.e317.

56. Hammond SM, Boettcher S, Caudy AA, Kobayashi R, Hannon GJ. Argonaute2, a link between genetic and biochemical analyses of RNAi. Science. 2001;293:1146-50.

57. Du H, Zhao Y, He J, Zhang Y, Xi H, Liu M, Ma J, Wu L. YTHDF2 destabilizes $m$ (6) A-containing RNA through direct recruitment of the CCR4-NOT deadenylase complex. Nat Commun. 2016;7:12626.

58. Jarrous N. Roles of RNase P and its subunits. Trends Genet. 2017:33:594-603.

59. Park OH, Ha H, Lee $\mathrm{Y}$, Boo SH, Kwon DH, Song HK, Kim YK. Endoribonucleolytic Cleavage of mA-Containing RNAs by RNase P/MRP Complex. Mol Cell. 2019;74:494-507.e498.

60. Liu CX, Li X, Nan F, Jiang S, Gao X, Guo SK, Xue W, Cui Y, Dong K, Ding H, et al. Structure and Degradation of Circular RNAs Regulate PKR Activation in Innate Immunity. Cell. 2019;177:865-880.e821.

61. Jia R, Xiao MS, Li Z, Shan G, Huang C. Defining an evolutionarily conserved role of GW182 in circular RNA degradation. Cell Discovery. 2019;5:45.

62. Fischer JW, Busa VF, Shao Y. Leung AKL. Structure-mediated RNA decay by UPF1 and G3BP1. Mol Cell. 2020;78(1):70-84.e6.

63. Shi $X$, Wang B, Feng $X, X u Y, L u K$, Sun M. circRNAs and Exosomes: a mysterious frontier for human Cancer. Mole Therapy Nucl Acids. 2020; 19:384-92.

64. Bai H, Lei K, Huang F, Jiang Z, Zhou X. Exo-circRNAs: a new paradigm for anticancer therapy. Mol Cancer. 2019;18:56.

65. Wang G, Liu W, Zou Y, Wang G, Deng Y, Luo J, Zhang Y, Li H, Zhang Q, Yang $Y$, Chen $G$. Three isoforms of exosomal circPTGR1 promote hepatocellular carcinoma metastasis via the miR449a-MET pathway. EBioMedicine. 2019;40:432-45.

66. Zhang H, Zhu L, Bai M, Liu Y, Zhan Y, Deng T, Yang H, Sun W, Wang X, Zhu $K$, et al. Exosomal circRNA derived from gastric tumor promotes white adipose browning by targeting the miR-133/PRDM16 pathway. Int J Cancer. 2019;144:2501-15.

67. Patop IL, Wüst $\mathrm{S}$, Kadener S. Past, present, and future of circRNAs. EMBO J. 2019;38:e100836

68. Zang J, Lu D, Xu A. The interaction of circRNAs and RNA binding proteins: an important part of circRNA maintenance and function. J Neurosci Res. 2020;98:87-97.

69. Tang Q, Hann SS. Biological roles and mechanisms of circular RNA in human cancers. OncoTargets Therapy. 2020;13:2067-92.

70. Huang C, Liang D, Tatomer DC, Wilusz JE. A length-dependent evolutionarily conserved pathway controls nuclear export of circular RNAs. Genes Dev. 2018;32:639-44.
71. Chen RX, Chen X, Xia LP, Zhang JX, Pan ZZ, Ma XD, Han K, Chen JW, Judde $\mathrm{JG}$, Deas $\mathrm{O}$, et al. N-methyladenosine modification of circNSUN2 facilitates cytoplasmic export and stabilizes HMGA2 to promote colorectal liver metastasis. Nat Commun. 2019;10:4695.

72. Xu C, Wang X, Liu K, Roundtree IA, Tempel W, Li Y, Lu Z, He C, Min J. Structural basis for selective binding of m6A RNA by the YTHDC1 YTH domain. Nat Chem Biol. 2014;10:927-9.

73. Lu T, Cui L, Zhou Y, Zhu C, Fan D, Gong H, Zhao Q, Zhou C, Zhao Y, Lu D, et al. Transcriptome-wide investigation of circular RNAs in rice. RNA. 2015; 21:2076-87.

74. Mao Y, Xu R. Circular RNA CDR1-AS contributes to pemetrexed and cisplatin chemoresistance through EGFR/PI3K signaling pathway in lung adenocarcinoma. Biomed Pharmacother. 2020;123:109771.

75. Yuan W, Zhou R, Wang J, Han J, Yang X, Yu H, Lu H, Zhang X, Li P, Tao J, et al. circular RNA Cdr1as sensitizes bladder cancer to cisplatin by upregulating APAF1 expression through miR-1270 inhibition. Mol Oncol. 2019;13:1559-76.

76. Zhao Z, Ji M, Wang Q, He N, Li Y. circular RNA Cdr1as Upregulates SCAI to suppress Cisplatin resistance in ovarian Cancer via miR-1270 suppression. Mol Therapy Nucl Acids. 2019;18:24-33.

77. Gao N, Ye B. Circ-SOX4 drives the tumorigenesis and development of lung adenocarcinoma via sponging miR-1270 and modulating PLAGL2 to activate WNT signaling pathway. Cancer Cell Int. 2020;20:2.

78. Zhong Z, Lv M, Chen J. Screening differential circular RNA expression profiles reveals the regulatory role of circTCF25-miR-103a-3p/miR-107-CDK6 pathway in bladder carcinoma. Sci Rep. 2016;6:30919.

79. Pan G, Mao A, Liu J, Lu J, Ding J, Liu W. Circular RNA hsa_circ_0061825 (circTFF1) contributes to breast cancer progression through targeting miR-326/ TFF1 signalling. Cell Prolif. 2020;53:e12720.

80. Wei S, Zheng Y, Jiang Y, Li X, Geng J, Shen Y, Li Q, Wang X, Zhao C, Chen Y, et al. The circRNA circPTPRA suppresses epithelial-mesenchymal transitioning and metastasis of NSCLC cells by sponging miR-96-5p. EBioMedicine. 2019;44:182-93.

81. Su Y, Feng W, Shi J, Chen L, Huang J, Lin T. circRIP2 accelerates bladder cancer progression via miR-1305/Tgf-32/smad3 pathway. Mol Cancer. 2020; 19:23.

82. Yang Z, Qu CB, Zhang Y, Zhang WF, Wang DD, Gao CC, Ma L, Chen JS, Liu KL, Zheng B, et al. Dysregulation of p53-RBM25-mediated circAMOTL1L biogenesis contributes to prostate cancer progression through the circAMOTL1L-miR-193a-5p-Pcdha pathway. Oncogene. 2019;38:2516-32.

83. Li Z, Huang C, Bao C, Chen L, Lin M, Wang X, Zhong G, Yu B, Hu W, Dai L, et al. exon-intron circular RNAs regulate transcription in the nucleus. Nat Struct Mol Biol. 2015;22:256-64.

84. Sun YM, Wang WT, Zeng ZC, Chen TQ, Han C, Pan Q, Huang W, Fang K, Sun $L Y$, Zhou YF, et al. circMYBL2, a circRNA from MYBL2, regulates FLT3 translation by recruiting PTBP1 to promote FLT3-ITD AML progression. Blood. 2019;134:1533-46.

85. Du WW, Yang W, Liu E, Yang Z, Dhaliwal P, Yang BB. Foxo3 circular RNA retards cell cycle progression via forming ternary complexes with p21 and CDK2. Nucleic Acids Res. 2016;44:2846-58.

86. Du WW, Fang L, Yang W, Wu N, Awan FM, Yang Z, Yang BB. Induction of tumor apoptosis through a circular RNA enhancing Foxo3 activity. Cell Death Differ. 2017;24:357-70.

87. Zhang M, Huang N, Yang X, Luo J, Yan S, Xiao F, Chen W, Gao X, Zhao $K$, Zhou $H$, et al. A novel protein encoded by the circular form of the SHPRH gene suppresses glioma tumorigenesis. Oncogene. 2018;37: 1805-14.

88. Zhang M, Zhao K, Xu X, Yang Y, Yan S, Wei P, Liu H, Xu J, Xiao F, Zhou $\mathrm{H}$, et al. A peptide encoded by circular form of LINC-PINT suppresses oncogenic transcriptional elongation in glioblastoma. Nat Commun. 2018:9:4475.

89. Yang Y, Gao X, Zhang M, Yan S, Sun C, Xiao F, Huang N, Yang X, Zhao K, Zhou $\mathrm{H}$, et al. Novel role of FBXW7 circular RNA in repressing Glioma tumorigenesis. J Natl Cancer Inst. 2018;110(3):304-15.

90. Yilmaz M, Christofori G. EMT, the cytoskeleton, and cancer cell invasion. Cancer Metastasis Rev. 2009;28:15-33.

91. Du WW, Yang W, Chen Y, Wu ZK, Foster FS, Yang Z, Li X, Yang BB. Foxo3 circular RNA promotes cardiac senescence by modulating multiple factors associated with stress and senescence responses. Eur Heart J. 2017;38:1402-12.

92. Cocquerelle C, Mascrez B, Hétuin D, Bailleul B. Mis-splicing yields circular RNA molecules. FASEB J. 1993;7:155-60. 
93. Abe N, Matsumoto K, Nishihara M, Nakano Y, Shibata A, Maruyama H, Shuto S, Matsuda A, Yoshida M, Ito Y, Abe H. Rolling Circle Translation of Circular RNA in Living Human Cells. Sci Rep. 2015;5:16435.

94. Lei M, Zheng G, Ning Q, Zheng J, Dong D. Translation and functional roles of circular RNAs in human cancer. Mol Cancer. 2020;19:30.

95. Wu P, Mo Y, Peng M, Tang T, Zhong Y, Deng X, Xiong F, Guo C, Wu X, Li Y, et al. Emerging role of tumor-related functional peptides encoded by IncRNA and circRNA. Mol Cancer. 2020;19:22.

96. Gross JD, Moerke NJ, von der Haar T, Lugovskoy AA, Sachs AB, McCarthy JE, Wagner G. Ribosome loading onto the mRNA cap is driven by conformational coupling between elF4G and elF4E. Cell. 2003; 115:739-50

97. Godet AC, David F, Hantelys F, Tatin F, Lacazette E, Garmy-Susini B, Prats AC. IRES trans-acting factors, key actors of the stress response. Int J Mol Sci. 2019:20(4):924

98. Holcik M. N Sonenberg: translational control in stress and apoptosis. Nat Rev Mol Cell Biol. 2005;6:318-27.

99. Pamudurti NR, Bartok O, Jens M, Ashwal-Fluss R, Stottmeister C, Ruhe L, Hanan M, Wyler E, Perez-Hernandez D, Ramberger E, et al. Translation of CircRNAs. Mol Cell. 2017;66:9-21.e27.

100. Petkovic S, Müller S. RNA circularization strategies in vivo and in vitro. Nucleic Acids Res. 2015;43:2454-65.

101. Wang Y, Wang Z. Efficient backsplicing produces translatable circular mRNAs. RNA. 2015;21:172-9.

102. Meyer KD, Patil DP, Zhou J, Zinoviev A, Skabkin MA, Elemento O, Pestova TV, Qian SB, Jaffrey SR. 5' UTR m (6) a promotes cap-independent translation. Cell. 2015;163:999-1010.

103. Roundtree IA, Evans ME, Pan T, He C. Dynamic RNA modifications in gene expression regulation. Cell. 2017;169:1187-200

104. Ries RJ, Zaccara S, Klein P, Olarerin-George A, Namkoong S, Pickering BF, Patil DP, Kwak H, Lee $J$, Jaffrey SR. mA enhances the phase separation potential of mRNA. Nature. 2019:571:424-8.

105. Yang $Y$, Fan $X$, Mao $M$, Song $X$, Wu $P$, Zhang $Y$, Jin $Y$, Yang $Y$, Chen $L L$, Wang $Y$, et al. extensive translation of circular RNAs driven by $\mathrm{N}-$ methyladenosine. Cell Res. 2017;27:626-41.

106. Guo JU, Agarwal V, Guo H, Bartel DP. Expanded identification and characterization of mammalian circular RNAs. Genome Biol. 2014;15:409.

107. You X, Vlatkovic I, Babic A, Will T, Epstein I, Tushev G, Akbalik G, Wang M, Glock C, Quedenau C, et al. Neural circular RNAs are derived from synaptic genes and regulated by development and plasticity. Nat Neurosci. 2015;18: 603-10.

108. Huang XX, Zhang Q, Hu H, Jin Y, Zeng AL, Xia YB, Xu L. A novel circular RNA circFN1 enhances cisplatin resistance in gastric cancer via sponging miR-182-5p. J Cell Biochem. 2020. https://doi.org/10.1002/jcb.29641.

109. Xiong W, Ai YQ, Li YF, Ye Q, Chen ZT, Qin JY, Liu QY, Wang H, Ju YH, Li WH, Li YF. Microarray analysis of circular RNA expression profile associated with 5-fluorouracil-based Chemoradiation resistance in colorectal Cancer cells. Biomed Res Int. 2017;2017:8421614.

110. Ren T, Liu C, Hou J, Shan F. Hsa_circ_0043265 suppresses proliferation, metastasis, EMT and promotes apoptosis in non-small cell lung Cancer through miR-25-3p/FOXP2 pathway. OncoTargets Therapy. 2020;13:3867-80.

111. Li Z, Hu Y, Zeng Q, Wang H, Yan J, Li H, Yu Z. Circular RNA MYLK promotes hepatocellular carcinoma progression by increasing Rab23 expression by sponging miR-362-3p. Cancer Cell Int. 2019;19:211.

112. Yang H, Li X, Meng Q, Sun H, Wu S, Hu W, Liu G, Li X, Yang Y, Chen R. CircPTK2 (hsa_circ_0005273) as a novel therapeutic target for metastatic colorectal cancer. Mol Cancer. 2020;19:13.

113. Guo X, Zhou Q, Su D, Luo Y, Fu Z, Huang L, Li Z, Jiang D, Kong Y, Li Z, et al. Circular RNA circBFAR promotes the progression of pancreatic ductal adenocarcinoma via the miR-34b-5p/MET/Akt axis. Mol Cancer. 2020;19:83.

114. Sun JW, Qiu S, Yang JY, Chen X, Li HX. Hsa_circ_0124055 and hsa_circ_ 0101622 regulate proliferation and apoptosis in thyroid cancer and serve as prognostic and diagnostic indicators. Eur Rev Med Pharmacol Sci. 2020;24: 4348-60.

115. Gao D, Zhang X, Liu B, Meng D, Fang K, Guo Z, Li L. Screening circular RNA related to chemotherapeutic resistance in breast cancer. Epigenomics. 2017; 9:1175-88.

116. Rao XCJ, Zhu H, Wang L, Liu L. Retraction: circular RNA-0007874 (circMTO1) reverses chemoresistance to temozolomide by acting as a sponge of microRNA-630 in glioblastoma. Cell Biol Int. 2018.
117. Wu Q, Wang H, Liu L, Zhu K, Yu W, Guo J. Hsa_circ_0001546 acts as a miRNA-421 sponge to inhibit the chemoresistance of gastric cancer cells via ATM/Chk2/p53-dependent pathway. Biochem Biophys Res Commun. 2020; 521:303-9.

118. Hu Y, Gu J, Shen H, Shao T, Li S, Wang W, Yu Z. Circular RNA LARP4 correlates with decreased Enneking stage, better histological response, and prolonged survival profiles, and it elevates chemosensitivity to cisplatin and doxorubicin via sponging microRNA-424 in osteosarcoma. J Clin Lab Anal. 2020;34:e23045

119. Zheng F, Xu R. CircPVT1 contributes to chemotherapy resistance of lung adenocarcinoma through miR-145-5p/ABCC1 axis. Biomed Pharmacother. 2020;124:109828.

120. Huang $W$, Yang $Y$, Wu J, Niu Y, Yao $Y$, Zhang J, Huang $X$, Liang $S$, Chen $R$, Chen S, Guo L. Circular RNA cESRP1 sensitises small cell lung cancer cells to chemotherapy by sponging miR-93-5p to inhibit TGF- $\beta$ signalling. Cell Death Differ. 2020;27(5):1709-27.

121. Li X, Yang B, Ren H, Xiao T, Zhang L, Li L, Li M, Wang X, Zhou H, Zhang W. Hsa_circ_0002483 inhibited the progression and enhanced the Taxol sensitivity of non-small cell lung cancer by targeting miR-182-5p. Cell Death Dis. 2019;10:953

122. Dong $Y, X u$ T, Zhong S, Wang B, Zhang H, Wang X, Wang P, Li G, Yang S. Circ_0076305 regulates cisplatin resistance of non-small cell lung cancer via positively modulating STAT3 by sponging miR-296-5p. Life Sci. 2019;239: 116984.

123. Xiao G, Huang W, Zhan Y, Li J, Tong W. CircRNA_103762 promotes multidrug resistance in NSCLC by targeting DNA damage inducible transcript 3 (CHOP). J Clin Lab Anal. 2020;34(6):e23252.

124. Huang MS, Liu JY, Xia XB, Liu YZ, Li X, Yin JY, Peng JB, Wu L, Zhang W, Zhou HH, Liu ZQ. Hsa_circ_0001946 inhibits lung Cancer progression and mediates Cisplatin sensitivity in non-small cell lung Cancer via the nucleotide excision repair signaling pathway. Front Oncol. 2019;9:508.

125. Liang Y, Song X, Li Y, Su P, Han D, Ma T, Guo R, Chen B, Zhao W, Sang Y, et al. circKDM4C suppresses tumor progression and attenuates doxorubicin resistance by regulating miR-548p/PBLD axis in breast cancer. Oncogene. 2019:38:6850-66.

126. Liu Y, Dong Y, Zhao L, Su L, Luo J. Circular RNA-MTO1 suppresses breast cancer cell viability and reverses monastrol resistance through regulating the TRAF4/Eg5 axis. Int J Oncol. 2018;53:1752-62.

127. Ma J, Fang L, Yang Q, Hibberd S, Du WW, Wu N, Yang BB. Posttranscriptional regulation of AKT by circular RNA angiomotin- like 1 mediates chemoresistance against paclitaxel in breast cancer cells. Aging. 2019;11:11369-81.

128. Yang W, Gong P, Yang Y, Yang C, Yang B, Ren L. Circ-ABCB10 contributes to paclitaxel resistance in breast Cancer through let-7a-5p/DUSP7 Axis. Cancer Manag Res. 2020;12:2327-37.

129. Shen Z, Zhou L, Zhang C, Xu J. Reduction of circular RNA Foxo3 promotes prostate cancer progression and chemoresistance to docetaxel. Cancer Lett. 2020;468:88-101.

130. Greene J, Baird AM, Casey O, Brady L, Blackshields G, Lim M, O'Brien O, Gray SG, McDermott R. SP Finn: Circular RNAs are differentially expressed in prostate cancer and are potentially associated with resistance to enzalutamide. Sci Rep. 2019;9:10739.

131. Wu G, Sun Y, Xiang Z, Wang K, Liu B, Xiao G, Niu Y, Wu D, Chang C. Preclinical study using circular RNA 17 and micro RNA 181c-5p to suppress the enzalutamide-resistant prostate cancer progression. Cell Death Dis. 2019;10:37.

132. Liu YY, Zhang LY, Du WZ. Circular RNA circ-PVT1 contributes to paclitaxel resistance of gastric cancer cells through the regulation of ZEB1 expression by sponging miR-124-3p. Biosci Rep. 2019;39(12):BSR20193045.

133. Huang X, Li Z, Zhang Q, Wang W, Li B, Wang L, Xu Z, Zeng A, Zhang $X$, Zhang $X$, et al. Circular RNA AKT3 upregulates PIK3R1 to enhance cisplatin resistance in gastric cancer via miR-198 suppression. Mol Cancer. 2019:18:71.

134. Zhang Q, Miao Y, Fu Q, Hu H, Chen H, Zeng A, Jin Y, Jiang Y, Qian L, Wu $\mathrm{L}$, et al. CircRNACCDC66 regulates cisplatin resistance in gastric cancer via the miR-618/BCL2 axis. Biochem Biophys Res Commun. 2020; 526(3):713-20.

135. Xu QY, Xie MJ, Huang J, Wang ZW. Effect of circ MTHFD2 on resistance to pemetrexed in gastric cancer through regulating expression of miR-124. Eur Rev Med Pharmacol Sci. 2019;23:10290-9. 
136. Ma L, Wang Z, Xie M, Quan Y, Zhu W, Yang F, Zhao C, Fan Y, Fang N, Jiang $\mathrm{H}$, et al. Silencing of circRACGAP1 sensitizes gastric cancer cells to apatinib via modulating autophagy by targeting miR-3657 and ATG7. Cell Death Dis. 2020;11:169.

137. Hon KW, Ab-Mutalib NS, Abdullah NMA, Jamal R, Abu N. Extracellular Vesicle-derived circular RNAs confers chemoresistance in Colorectal cancer. Sci Rep. 2019;9:16497.

138. Wang X, Zhang H, Yang H, Bai M, Ning T, Deng T, Liu R, Fan Q, Zhu K, Li J, et al. Exosome-delivered circRNA promotes glycolysis to induce chemoresistance through the miR-122-PKM2 axis in colorectal cancer. Mol Oncol. 2020;14:539-55.

139. Lai M, Liu G, Li R, Bai H, Zhao J, Xiao P, Mei J. Hsa_circ_0079662 induces the resistance mechanism of the chemotherapy drug oxaliplatin through the TNF-a pathway in human colon cancer. J Cell Mol Med. 2020;24:5021-7.

140. Zhang H, Yan J, Lang X, Zhuang Y. Expression of circ_001569 is upregulated in osteosarcoma and promotes cell proliferation and cisplatin resistance by activating the Wnt/ $\beta$-catenin signaling pathway. Oncol Lett. 2018;16:585662.

141. Liu J, Xue N, Guo Y, Niu K, Gao L, Zhang S, Gu H, Wang X, Zhao D, Fan R. CircRNA_100367 regulated the radiation sensitivity of esophageal squamous cell carcinomas through miR-217/Wnt3 pathway. Aging. 2019;11:12412-27.

142. Li J, Yang J, Zhou P, Le Y, Zhou C, Wang S, Xu D, Lin HK, Gong Z. circular RNAs in cancer: novel insights into origins, properties, functions and implications. Am J Cancer Res. 2015;5:472-80.

143. Zou FW, Yang SZ, Li WY, Liu CY, Liu XH, Hu CH, Liu ZH, Xu S. circRNA_ 001275 upregulates Wnt7a expression by competitively sponging miR-370$3 p$ to promote cisplatin resistance in esophageal cancer. Int J Oncol. 2020; 57:151-60.

144. Hong $X$, Liu N, Liang Y, He Q, Yang X, Lei Y, Zhang P, Zhao Y, He S, Wang Y, et al. circular RNA CRIM1 functions as a ceRNA to promote nasopharyngeal carcinoma metastasis and docetaxel chemoresistance through upregulating FOXQ1. Mol Cancer. 2020;19:33.

145. Chi BJ, Zhao DM, Liu L, Yin XZ, Wang FF, Bi S, Gui SL, Zhou SB, Qin WB, Wu DM, Wang SQ. Downregulation of hsa_circ_0000285 serves as a prognostic biomarker for bladder cancer and is involved in cisplatin resistance. Neoplasma. 2019;66:197-202.

146. Zhang S, Cheng J, Quan C, Wen H, Feng Z, Hu Q, Zhu J, Huang Y, Wu X. circCELSR1 (hsa_circ_0063809) contributes to paclitaxel resistance of ovarian Cancer cells by regulating FOXR2 expression via miR-1252. Mole Therapy Nucl Acids. 2019;19:718-30.

147. Shang J, Chen WM, Wang ZH, Wei TN, Chen ZZ, Wu WB. CircPAN3 mediates drug resistance in acute myeloid leukemia through the miR-153-5p/miR183-5p-XIAP axis. Exp Hematol. 2019;70:42-54.e43.

148. Shang J, Chen WM, Liu S, Wang ZH, Wei TN, Chen ZZ, Wu WB. CircPAN3 contributes to drug resistance in acute myeloid leukemia through regulation of autophagy. Leuk Res. 2019;85:106198.

149. Cao HX, Miao CF, Sang LN, Huang YM, Zhang R, Sun L. Jiang ZX. Life Sci. 2020;243:117255

150. Pan Y, Lou J, Wang H, An N, Chen H, Zhang Q, Du X. CircBA9.3 supports the survival of leukaemic cells by up-regulating c-ABL1 or BCR-ABL1 protein levels. Blood Cells Mol Dis. 2018;73:38-44.

151. Ping L, Jian-Jun C, Chu-Shu L, Guang-Hua L, Ming Z. High circ_100053 predicts a poor outcome for chronic myeloid leukemia and is involved in imatinib resistance. Oncol Res. 2019. https://doi.org/10.3727/ $096504018 \times 15412701483326$.

152. Gao M, Li C, Xiao H, Dong H, Jiang S, Fu Y, Gong L. hsa_circ_0007841: a novel potential biomarker and drug resistance for multiple myeloma. Front Oncol. 2019;9:1261.

153. Liu Y, Xia L, Dong L, Wang J, Xiao Q, Yu X, Zhu H. CircHIPK3 promotes gemcitabine (GEM) resistance in pancreatic Cancer cells by sponging miR330-5p and targets RASSF1. Cancer Manag Res. 2020;12:921-9.

154. Lu Q, Fang T. Circular RNA SMARCA5 correlates with favorable clinical tumor features and prognosis, and increases chemotherapy sensitivity in intrahepatic cholangiocarcinoma. J Clin Lab Anal. 2019;34(4):e23138.

155. Chen H, Liu S, Li M, Huang P, Li X. circ_0003418 inhibits tumorigenesis and Cisplatin Chemoresistance through Wnt/B-catenin pathway in hepatocellular carcinoma. OncoTargets Therapy. 2019;12:9539-49.

156. Yan L, Liu G, Cao H, Zhang H, Shao F. Hsa circ 0035483 sponges hsa-miR335 to promote the gemcitabine-resistance of human renal cancer cells by autophagy regulation. Biochem Biophys Res Commun. 2019;519:172-8.
157. Ding C, Yi X, Wu X, Bu X, Wang D, Wu Z, Zhang G, Gu J, Kang D. Exosomemediated transfer of circRNA CircNFIX enhances temozolomide resistance in glioma. Cancer Lett. 2020;479:1-12.

158. Meador CB. AN Hata: acquired resistance to targeted therapies in NSCLC: updates and evolving insights. Pharmacol Ther. 2020;210:107522.

159. Iyer AK, Singh A, Ganta S, Amiji MM. Role of integrated cancer nanomedicine in overcoming drug resistance. Adv Drug Deliv Rev. 2013;65: 1784-802.

160. Katsurada N, Tachihara M, Hatakeyama Y, Koyama K, Yumura M, Kiriu T, Dokuni R, Hazama D, Tokunaga S, Tamura D, et al. Feasibility study of adjuvant chemotherapy with carboplatin and nab-paclitaxel for completely resected NSCLC. Cancer Manag Res. 2020;12:777-82.

161. Akram M, lqbal M, Daniyal M. AU Khan: Awareness and current knowledge of breast cancer. Biol Res. 2017;50:33.

162. Raychaudhuri M, Bronger H, Buchner T, Kiechle M, Weichert W, Avril S MicroRNAs miR-7 and miR-340 predict response to neoadjuvant chemotherapy in breast cancer. Breast Cancer Res Treat. 2017;162:511-21.

163. Egan A, Dong Y, Zhang H, Qi Y, Balk SP, Sartor O. Castration-resistant prostate cancer: adaptive responses in the androgen axis. Cancer Treat Rev. 2014:40:426-33.

164. Okugawa Y, Mohri Y, Tanaka K, Kawamura M, Saigusa S, Toiyama Y, Ohi M, Inoue $Y$, Miki C, Kusunoki M. Metastasis-associated protein is a predictive biomarker for metastasis and recurrence in gastric cancer. Oncol Rep. 2016; 36:1893-900.

165. Yu J, Hu F, Zhu Q, Li X, Ren H, Fan S, Qian B, Zhai B, Yang D. PD-L1 monoclonal antibody-decorated nanoliposomes loaded with paclitaxel and P-gp transport inhibitor for the synergistic chemotherapy against multidrug resistant gastric cancers. Nanoscale Res Lett. 2020;15:59.

166. Zhang J, Liu H, Hou L, Wang G, Zhang R, Huang Y, Chen X, Zhu J. Circular RNA_LARP4 inhibits cell proliferation and invasion of gastric cancer by sponging miR-424-5p and regulating LATS1 expression. Mol Cancer. 2017; 16:151.

167. Lin W, Ye H, You K, Chen L. Up-regulation of circ_LARP4 suppresses cell proliferation and migration in ovarian cancer by regulating miR-513b-5p/ LARP4 axis. Cancer Cell Int. 2020;20:5.

168. Chen Z, Yao N, Gu H, Song Y, Ye Z, Li L, Lu P, Shao Q. circular RNA_LARP4 sponges miR-1323 and hampers progression of esophageal squamous cell carcinoma through modulating PTEN/PI3K/AKT pathway. Dig Dis Sci. 2020 https://doi.org/10.1007/s10620-019-05973-0.

169. Chen GZ, Zhu HC, Dai WS, Zeng XN, Luo JH, Sun XC. The mechanisms of radioresistance in esophageal squamous cell carcinoma and current strategies in radiosensitivity. J Thoracic Dis. 2017;9:849-59.

170. Bladder cancer: diagnosis and management of bladder cancer. ( ) NICE (2015) Bladder cancer: diagnosis and management of bladder cancer. BJU Int. 2017;120(6):755-65.

171. Li XX, Zhou JD, Wen XM, Zhang TJ, Wu DH, Deng ZQ, Zhang ZH, Lian XY, He PF, Yao XY, et al. MCL-1Increased expression predicts poor prognosis and disease recurrence in acute myeloid leukemia. OncoTargets Therapy. 2019;12:3295-304

172. Kaleem B, Shahab S, Ahmed N, Shamsi TS. chronic myeloid leukemia-prognostic value of mutations. Asian Pac J Cancer Prev. 2015;16:7415-23.

173. Zhou T. LJ Medeiros, S Hu: chronic myeloid leukemia: beyond BCR-ABL1. Curr Hematol Malig Rep. 2018;13:435-45.

174. Yap E, Norziha ZA, Simbun A, Tumian NR, Cheong SK, Leong CF, Wong CL. MicroRNAs that affect the Fanconi anemia/BRCA pathway are downregulated in imatinib-resistant chronic myeloid leukemia patients without detectable BCR-ABL kinase domain mutations. Leuk Res. 2017;59: 32-40.

175. Robak P, Drozdz I, Szemraj J, Robak T. Drug resistance in multiple myeloma Cancer Treat Rev. 2018;70:199-208.

\section{Publisher's Note}

Springer Nature remains neutral with regard to jurisdictional claims in published maps and institutional affiliations. 